\title{
The effects of Mn concentration on the tribocorrosion resistance of Al-Mn alloys
}

\author{
Hesham Mraied and Wenjun Cai ${ }^{1}$ \\ Department of Mechanical Engineering, University of South Florida, $4202 \mathrm{E}$ \\ Fowler Avenue, Tampa, FL 33620, USA
}

\begin{abstract}
An increase in the complexity and severity of service conditions demands improvements in the design of new engineering materials that are resistant to the effects of tribocorrosion. Unfortunately, there is typically a tradeoff between wear and corrosion resistance, even for important passive metals such as Al alloys. In this work, it was shown that alloying $\mathrm{Al}$ with $\mathrm{Mn}$ in supersaturated solid solution simultaneously increased the wear resistance of the Al as well as the protectiveness of the passive layer, thus improving the overall tribocorrosion resistance. Specifically, the effects of $\mathrm{Mn}$ alloying on the tribocorrosion behavior of magnetron-sputtered Al$\mathrm{Mn}$ thin films with 5.2 at.\% and 20.5 at.\% $\mathrm{Mn}$ were investigated in a $0.6 \mathrm{M} \mathrm{NaCl}$ aqueous solution. Tribocorrosion resistance was found to be strongly affected by the alloying concentration and applied potential. Higher Mn content increased the ratio of hardness to elastic modulus $(\mathrm{H} / \mathrm{E})$ and promoted the formation of denser and more compact passive film, hence improving tribocorrosion resistance of Al. In particular, alloying with 20.5 at.\% Mn led to an increase of the corrosion resistance by $\sim 10$ times and the hardness by $\sim 8$ times compared to pure Al. The total material loss during tribocorrosion was found to increase with the anodic shift of the applied potential. A galvanic cell model was used to investigate the depassivationrepassivation kinetics during tribocorrosion. It was found that alloying with 5.2 at.\% Mn led to more than 10-fold reduction in the current density required to re-passivate similar worn areas of pure Al. Finally, the origin of wear-corrosion synergy was discussed based on these observations.
\end{abstract}

Keywords: Aluminum alloys; composition; wear; tribocorrosion

\footnotetext{
${ }^{1}$ Email: caiw@usf.edu, phone: 813-974-7909
} 


\section{Introduction}

Tribocorrosion, i.e. material degradation caused by the synergistic effects of wear and corrosion, is prominent for passive metals such as $\mathrm{Al}$, $\mathrm{Ti}$ alloys, and stainless steel [1, 2], which spontaneously form an amorphous semiconducting oxide film (passive film) when in contact with oxygen or water due to their high negative free energy of formation [3]. This passive film, sometimes only a few atomic layers thick, acts as a critical protective barrier against corrosion [2, 3]. During tribocorrosion, the mechanical wear locally destroys the passive film at the contacting asperities, leading to rapid localized corrosion on the depassivated area and early component failure $[4,5]$. Thus a better understanding of the tribocorrosion response of passive metals, e.g. Al alloys, is required to extend the durability of these technologically important metals in complex service conditions such as in biomedical implants, hydraulic systems, nuclear power plants, marine and offshore industries etc. [6].

Tribocorrosion resistance of passive metals not only depends on material properties (e.g. microstructure, strength, work-hardening ability), but also on environment (e.g. pH, humidity, oxygen concentration) and testing conditions (e.g. applied potential, load, and sliding speed) [7]. In addition, the problem is further complicated by the fact that the chemical and mechanical attacks are not independent of each other, but often act synergistically to cause accelerated failure $[4,6]$. This synergy is often related to various events such as the localized deterioration of the passive film [8], wear debris acting as a third body between the contacting surfaces [9], and material transfer to the counter body due to plastic deformation [10].

This work focuses on studying the alloying effect on the tribocorrosion resistance of Al alloy. Owing to the formation of protective passive film in neutral $(\mathrm{pH} \mathrm{4-9)} \mathrm{solutions} \mathrm{[11],} \mathrm{Al} \mathrm{is} \mathrm{a} \mathrm{good}$ candidate for replacing toxic cadmium coatings, and is widely used for corrosion protection of steel [12], magnesium alloys [13], and NdFeB magnets [14] etc. Unfortunately pure Al is highly susceptible to wear due to its low hardness, thus greatly limit the durability and lifetime of such coatings. Alloying is an effective way to improve materials' wear resistance by increasing the hardness per Archard's law (i.e. wear rate is inversely related to hardness) [15]. In addition to hardness increment, proper alloying additions can significantly lower the grain boundary energy and stabilize ultrafine microstructures in the tribolayer, thus suppressing unfavorable stressassisted grain growth during wear [16]. While most commercial Al alloys are precipitationhardened to impart good strength and wear resistance, none of them have very good resistance against localized corrosion. The precipitation strengthens the material but, at the same time, enhances corrosion by forming unfavorable galvanic coupling with the Al matrix [11]. Recent studies showed that appropriate alloying additions can enhance the pitting resistance of Al as long as the alloying elements are retained in solid solution with Al without phase separation [1720]. For example, age-hardened Al-Cu alloys exhibit poor corrosion resistance [11], but Kim et al. observed an ennoblement of pitting potential with increasing $\mathrm{Cu}$ content in $\mathrm{Al}-\mathrm{Cu}$ solid solutions [17, 18]. Similarly, Al-based high entropy alloys such as $\mathrm{Al}_{\mathrm{x}} \mathrm{Co}_{1.5} \mathrm{CrFeNi}_{1.5} \mathrm{Ti}_{\mathrm{y}}$, which form a supersaturated solid solution, exhibit remarkable wear and corrosion resistance [21-23].

Current research in tribocorrosion response of Al alloys is very limited in scope. Abundant literature exists pertaining to the possible alloying effects on wear and corrosion resistance, but 
few attempts have been made to combine knowledge based on these two separated fields towards a better understanding of tribocorrosion. Even though there is no unified theory at the moment, the evidence indicates an exciting opportunity to alloy Al to optimize both wear and corrosion resistance. Fig. 1 summarizes alloying effects on hardness, pitting potential and corrosion current density of Al-TM (transition metal) reported so far [19, 24-32]. It can be seen that higher alloying content improves hardness, hence is likely to enhance wear resistance, although the optimum alloy concentration is not known a priori due to complicated dynamic microstructure evolution (e.g. dislocation accumulation due to sustained plastic deformation vs. stress-assisted grain growth and dynamic recovery) in the tribolayer [16]. On the other hand, alloying may affect corrosion resistance of $\mathrm{Al}$ in different ways depending on the specific alloying elements, as reviewed by Szklarska-Smialowska [33]. Small quantities of Sn, In, Hg, Ga, and $\mathrm{Zn}$ are detrimental to Al corrosion, as they reduce the passive potential region and shift the corrosion and pitting potentials in the negative direction [34]. Thus these TMs lead to high anodic current density and uniform active surface corrosion. Other TMs such as $\mathrm{Cu}, \mathrm{Cr}, \mathrm{Mo}, \mathrm{Mn}$, $\mathrm{Nb}$, and $\mathrm{W}$ enhance corrosion resistance by decreasing metastable pit initiation and growth rates of $\mathrm{Al}$ [17]. Furthermore, as shown in Fig. 1(b)(c), the pitting potential of Al-TM generally increases with alloy concentration although the corrosion current remain scattered.

The above discussion suggests a great opportunity of combating tribocorrosion by alloying Al with appropriate TMs in solid solution. This work combines tribological and electrochemical methods to evaluate the fundamental deformation and degradation mechanism during tribocorrosion of aluminum-manganese (AI-Mn) solid solutions. The corrosion behavior of Al-Mn has been studied extensively previously [24, 35-37], but the tribocorrosion resistance of this system has not yet been reported before. Al-Mn alloys were prepared by magnetron sputtering. The high effective quench rate during physical vapor deposition allows the generation of high levels of supersaturation of low-miscibility substitutional alloying elements, which is essential in promoting chemically homogenous nanocrystalline or glassy phase formation far beyond the equilibrium solubility limit [25]. The alloying element (Mn) was selected based on the following criteria: 1) excellent microstructure stability due to high grain boundary segregation enthalpy of $\mathrm{Mn}$ in $\mathrm{Al}[38,39], 2$ ) high ionic potential of $\mathrm{Mn}_{\mathrm{x}} \mathrm{O}_{\mathrm{y}}$ (e.g. 17.95 for $\mathrm{Mn}_{2} \mathrm{O}_{7}$ and 15.19 for $\mathrm{MnO}_{3}$ ), indicating good oxide film lubricity [40], 3) similar atomic radii as Al (atomic radii ratio $r_{\mathrm{Mn}} / \mathrm{r}_{\mathrm{Al}}=$ 1.12) that favors high non-equilibrium solubility, and 4) a wide range of equilibrium phases that could be formed in Al-Mn binary system [41], which allows tunable microstructure via alloying $[25,42]$. We hypothesize that alloying elements that satisfy these criteria have a potential to increase tribocorrosion resistance of Al. In this work, we focused on two compositions: $~ 5.2$ at.\% and 20.5 at.\% $\mathrm{Mn}$, which showed high corrosion resistance for Al-Mn with up to 20 at.\% $\mathrm{Mn}$ [24]. While we focused on a binary system here, it is believed that the generated understanding could also benefit the design of more complicated solid solution systems in the future, such as Al-based bulk metallic glass and high entropy alloys.

\section{Materials and methods}

2.1. Materials synthesis, characterization, and mechanical testing 
Pure $\mathrm{Al}$ and $\mathrm{Al}-\mathrm{Mn}$ thin films with 5.2 at.\% and 20.5 at.\% Mn were prepared by RF magnetron sputtering on (100) Si substrate. Sputtering was carried out inside a vacuum chamber (CRC100 sputtering coater, Torr International, New York, USA) at $80 \mathrm{~W}$ input power under 5 mTorr argon atmosphere (99.99\%). All metallic film thicknesses were kept at $\sim 1.2 \mu \mathrm{m}$, as measured using a (Dektak D150 Profiler, Veeco, New York, USA). The sample surface morphology and chemical composition before and after tribocorrosion tests were characterized using a scanning electron microscopy (SEM, SU-70, Hitachi, California, USA) and an energy-dispersive X-ray spectroscopy (EDS, EDAX-Phoenix, New Jersey, USA). Post-tribocorrosion cross-sectional samples were prepared from areas inside the wear-track using a Dual Beam focused ion beam microscope (FIB, Quanta 200 3D, Oregon, USA). Nanoindentation tests were performed using a triboindenter (Ti900, Hysitron, Minnesota, USA) with a diamond Berkovich tip ( 125 nm radius). All indentations were carried out under a trapezoidal loading profile with $3 \mathrm{mN}$ maximum load, $0.05 \mathrm{~N} / \mathrm{s}$ loading/unloading rate, and $5 \mathrm{~s}$ holding time. The penetration depth was kept below $10 \%$ of total film thickness to eliminate the substrate effect. The hardness was obtained following Oliver-Pharr method [43]. The reported value of hardness is the average of at least 20 measurements. Detailed descriptions on the synthesis of Al and Al-Mn thin films, together with the effect of alloying Al with Mn on the microstructure and surface morphology has been already discussed in a previous publication $[\mathrm{x}]$.

\subsection{Electrochemical and tribocorrosion tests}

A protective stop-off lacquer was applied to the sample surface to expose an effective area of $\sim 1 \mathrm{~cm}^{2}$ for the electrochemical tests and $\sim 1.8 \mathrm{~cm}^{2}$ for the tribocorrosion tests. The electrochemical measurements were conducted in a typical three electrode configuration at ambient temperature in naturally aerated stagnant $0.6 \mathrm{M} \mathrm{NaCl}$ aqueous solution with a pH value of about 6.4 using a potentiostat (model $600 \AA$, Gamry, Pennsylvania, USA). The as-sputtered samples served as the working electrode, while the mixed metal oxide coated titanium mesh, and a commercial $1 \mathrm{M} \mathrm{KCl}$ silver-silver chloride electrode used as the counter, and reference electrode, respectively. Potentiodynamic polarization (PD) experiments were conducted after allowing for the stability of the open circuit potential $\left(E_{O C}\right)$. The scan rate was $0.167 \mathrm{mV} / \mathrm{s}$, starting at a potential $\sim 150 \mathrm{mV}$ cathodic to $\mathrm{E}_{\mathrm{OC}}$ and terminated once the anodic current density reached $\sim 10 \mu \mathrm{A} \cdot \mathrm{cm}^{-2}$. To examine the behavior of the passive film, electrochemical impedance spectroscopy (EIS) and Mott-Schottky (MS) analysis were conducted following potentiostatic (PS) anodic polarization. EIS tests were conducted at $\mathrm{E}_{\mathrm{OC}}$ in the frequency range of $100 \mathrm{kHz}$ to $10 \mathrm{mHz}, 5$ points per decade, and $10 \mathrm{mV}_{\mathrm{rms}}$ sinusoidal potential excitation. The obtained data was then fitted using Gamry E-chem software. The PS analysis was conducted for 60 min with a sample period of $10 \mathrm{~Hz}$ at a fixed potential of $200 \mathrm{mV}$ vs. EOC within the passive region to produce a compact and dense passive film. MS tests were conducted from 0 to $300 \mathrm{mV}$ vs. E in the anodic region at $1 \mathrm{kHz}$ frequency, amplitude of $10 \mathrm{mV}_{\mathrm{rms}}$, and potential sweeping rate of $10 \mathrm{mV} / \mathrm{s}$.

Tribocorrosion tests were carried out in a reciprocating ball-on-plate mode with alumina ball $\left(\mathrm{Al}_{2} \mathrm{O}_{3}, \varnothing 4 \mathrm{~mm}\right)$ as the counter piece using a Universal Mechanical Tester (UMT-2, Bruker, California, USA) apparatus with a custom-made tribocorrosion cell, as shown in Fig. 2. This UMT has ultra-accurate strain gauge sensor to measure the force and torque. The sensor 
provides feedback to a vertical motion controller. The tester is also equipped with fully automated PC-based motor control and data acquisition. The force sensing resolution is $50 \mu \mathrm{N}$ and $50 \mathrm{mN}$ for load ranges of $5-500 \mathrm{mN}$ and $10-1000 \mathrm{~N}$, respectively. Each test was carried out at $5 \mathrm{~mm}$ stroke length, $5 \mathrm{~mm} / \mathrm{s}$ sliding velocity, under $0.5 \mathrm{~N}$ normal load (corresponds to initial mean Hertzian contact pressure of $0.47 \mathrm{GPa}$ ) at various potentials ( $E_{\mathrm{OC}}$, anodic and cathodic potentials) following the hereafter sequence; $\mathrm{E}_{\mathrm{OC}}$ stabilization for $20 \mathrm{~min}$, application of a specified potential for $20 \mathrm{~min}$, application of reciprocating load for $5 \mathrm{~min}$, re-passivation at the same potential for $5 \mathrm{~min}$. The anodic potential $\left(200 \mathrm{mV}\right.$ above $\mathrm{E}_{\mathrm{oc}}$ ) was selected within the passive region below the pitting potentials and the cathodic potential ( $350 \mathrm{mV}$ below $\mathrm{E}_{\mathrm{oc}}$ ) was chosen to avoid hydrogen evolution reaction during sliding, which might lead to embrittlement of the samples [44]. Pure Al was not tested in the anodic regime due to its active anodic dissolution. A new alumina ball was used for each test to minimize contamination. After the tribocorrosion tests, wear track dimensions were measured using a Dektak D150 profilometer from three different locations along the wear track for each sample. The wear track crosssectional area (i.e. wear track width times sample height loss) was then calculated using the trapezoidal numerical integration method. Total material loss rate (total loss in volume /sliding distance) was calculated by the multiplication of the cross-sectional area and the wear track length, then dividing by the total sliding distance. All electrochemical and tribocorrosion test results reported hereafter correspond to the average from at least three separate samples at each test condition.

\section{Results and discussion}

\subsection{Structure and property of as-deposited Al-Mn}

Detailed characterization of the microstructure of $\mathrm{Al}$ and $\mathrm{Al}-\mathrm{Mn}$ alloys has been previously reported [45]. We briefly recall here that all as-deposited Al-Mn formed chemically homogenous supersaturated solid solutions. Increasing $\mathrm{Mn}$ concentration led to the formation of nanocrystalline (5.2 at.\% Mn) and fully amorphous (20.5 at.\% $\mathrm{Mn}$ ) microstructures. The average grain size of pure Al and A5 was $42 \pm 11.5$ and $15 \pm 6.2 \mathrm{~nm}$ respectively. The hardness of pure Al $(0.67 \pm 0.18 \mathrm{GPa})$ was increased to $1.58 \pm 0.13 \mathrm{GPa}$ and $5.41 \pm 0.15 \mathrm{GPa}$ for A5 and A20, respectively. This behavior is similar to that reported in PVD sputtered [35] and electrodeposited $[25,46]$ Al-Mn alloys. The increase in hardness could be related to solid solution strengthening, structure refinement, and the increase of average bond strength with increasing $\mathrm{Mn}$ concentration, as shown recently by Wang et al. via first-principles calculations [47]. The H/E ratio, which is often related to materials' wear resistance [48], is 0.020 and 0.056 for A5 and A20 respectively, as compared to 0.009 for pure Al. This increase in $\mathrm{H} / \mathrm{E}$ indicates an enhanced wear resistance and coating durability via Mn alloying, as confirmed later in section 3.3.

\subsection{Corrosion behavior}

Prior to tribocorrosion study, the effects of Mn addition on the corrosion resistance of Al were evaluated using PD tests, as summarized in Table 1. The typical PD curves of all samples after $1 \mathrm{hr}$ immersion in 0.6 M NaCl solution are shown in Fig. 3. For comparison, the typical behavior of bulk cast $\mathrm{Al}(99.99 \%)$ is also presented. It can be seen that pure Al (either deposited or cast) 
showed highly active dissolution in the electrolyte at the anodic region with no indication of passivation. Similar behavior has also been reported for Al alloys in aerated halide solutions [49, 50], suggesting that the cathodic oxygen reduction is sufficient to raise the corrosion potential to the pitting potential. On the other hand, both A5 and A20 showed a typical behavior of alloy that has a clear distinguishable passive behavior indicated by the sharp increase in potential at constant current density, followed by rapid increase in current density at constant potential i.e the pitting potential $\left(E_{\text {pit }}\right)$. The amorphous alloy $A 20$ exhibited the highest $E_{\text {pit }}$ due to the high $M n$ content, similar to that reported elsewhere [35, 37]. At $E_{o c}, A 5$ and $A 20$ exhibited a reduction in corrosion current density ( $\mathrm{i}_{\text {corr }}$ ) and an anodic shift of the crossover potentials for zero current ( $E_{\text {zero current }}$ ) compared to pure $\mathrm{Al}$, indicating the passive behavior of Al-Mn alloys. From the above results it can be seen that $\mathrm{Mn}$ addition enhanced corrosion resistance and decreased pitting susceptibility of $\mathrm{Al}$, similar to that reported in other Al-TM (TM = Ta, Mo, Cu, W, etc.) systems [33].

\subsubsection{Potentiostatic (PS) anodic polarization}

Alloying additions often affect corrosion resistance by modifying the passive film properties. To evaluate the effect of $\mathrm{Mn}$ concentration on passive film protectiveness of Al, potentiostatic (PS) anodic polarization tests were carried out. Fig. 4 shows the evolution of current density as a function of time for A5 and A20 at $200 \mathrm{mV}$ above their respective $\mathrm{E}_{\mathrm{OC}}$. These applied potentials were chosen within the passive region well below the pitting potential, where the current density is largely independent of potential. Hence in this work, by applying the same anodic overpotential, the difference in passive film thickening behavior of A5 and A20 can be mainly attributed to the difference in alloy composition, not applied potential. In PS experiments, the current density ( $i$ ) could be represented as [51]:

$$
i=A t^{-k}
$$

where $t$ is the time, $k$ is the slope of the curve in the double logarithmic $i-t$ plot, and $A$ is a constant that depends on the potential and electrolyte concentration. The value of $k$ was used to indicate the compactness of the passive film, where generally $k=0$ indicates an actively corroding alloy, while $k=-0.5$ and -1 indicates the formation of porous and protective oxide film, respectively. It is also noted that a deviation from $k=-1$ could also indicate partial uniform dissolution of the passive film during growth. From Fig. 4 it can be seen that both alloys showed a decrease in the current density as time proceeded, suggesting the continuous growth of the passive film throughout the entire time of anodic polarization. In addition, A20 exhibited more negative slopes (-0.79 and -0.96) compared to A5 (-0.39 and -0.49$)$, indicating the formation of denser and more protective passive film at higher $\mathrm{Mn} \%$.

\subsubsection{EIS measurements}

To evaluate the corrosion resistance of the polarized AI-Mn, EIS measurements were conducted after the PS test. The Nyquist representation of the results (Fig. 5) shows a single capacitive semicircle, confirming the presence of protective passive film for both alloys. in addition, the diameter of the capacitive semicircles increases with Mn addition, indicating an increase in the corrosion resistance at higher $\mathrm{Mn} \%$. The experimental results were fitted using an equivalent 
circuit model, as shown in Fig. 5 inset, where $R_{s}$ represents the ohmic solution resistance, $C E_{1}$ (constant phase element) represents the somewhat nearly-ideal capacitive behavior of the passive film [14]. That component, in combination with the charge transfer resistance $R_{1}$, accounts for the time constant of the high frequency semicircle. $R_{1}$ may be considered as being representative of a conductive path through imperfections of the passive film that may reflect breakdown ranging from incipient (largest values of $R_{1}$ ) through more advanced (smaller values) paths. $R_{1}$ is in series with the components of the time constant at low frequency $C P E_{2}$ and $R_{2}$ which correspond to the double layer capacitor at the metal surface. The summation of $R_{1}$ and $R_{2}$ could be considered as the overall impedance and represent the polarization resistance $\left(R_{p}\right)$ of the system [52].

The impedance of the CPE can be represented as follows [53]:

$$
Z_{C P E}=Y_{o}^{-1}(j \omega)^{-n},
$$

where $Y_{o}$ is a constant that represents the interfacial properties, $j$ is an imaginary unit, $\omega$ is angular frequency, and $n$ is a real number ranges between ( 0 and 1$)$ that represents the heterogeneity of the surface. The modeled curves using this proposed equivalent analog circuit are plotted as solid lines in Fig. 5.

The nominal thickness of the passive film can be estimated from;

$$
d=\varepsilon \varepsilon_{0} A / C,
$$

where $\varepsilon$ is the dielectric constant of the passive film (10 for aluminum oxide [54]), $\varepsilon_{o}$ is the permittivity of vacuum $\left(8.85 \times 10^{-14} \mathrm{~F} \cdot \mathrm{cm}^{-1}\right), A$ is the exposed surface area $\left(\sim 1 \mathrm{~cm}^{2}\right)$ and $C$ is the capacitance evaluated from $\mathrm{CPE}_{1}$. The equivalent circuit fitting parameters are shown in Fig. 6. It can be seen that for all fitting parameters $\left(R_{1}, Y_{0}\right.$, and $\left.n\right), A 20$ is higher than $A 5$, indicating the formation of a more homogenous passive film with higher polarization resistance. In addition, the passive film thickness of A20 is $\sim 1.2 \mathrm{~nm}$, much higher than that of A5 $(\sim 0.6 \mathrm{~nm})$.

\subsubsection{Mott-Schottky (MS) analysis}

Passive films on most metals and alloys are semiconducting, albeit often highly defective. The formation and breakdown of passive film strongly depends on the semiconducting nature of the passive film, which can be evaluated using Mott-Schottky (MS) analysis. During MS test, the electronic properties of the passive film could be evaluated using the following equations [55-59]

$$
\frac{1}{C^{2}}=\frac{2}{\varepsilon \varepsilon_{0} e N_{d}}\left(E-E_{f b}-\frac{K T}{e}\right) \quad \text { for } \mathrm{n} \text {-type semiconductor behavior }
$$

and, $\quad \frac{1}{C^{2}}=\frac{-2}{\varepsilon \varepsilon_{0} e N_{a}}\left(E-E_{f b}-\frac{K T}{e}\right) \quad$ for p-type semiconductor behavior

where $C$ is the capacitance, $\varepsilon$ is the dielectric constant of the passive film (10 for $\mathrm{A}_{12} \mathrm{O}_{3}$ [54]), $\varepsilon_{0}$ is the permittivity of vacuum $\left(8.85 \times 10^{-14} \mathrm{Fcm}^{-1}\right), N_{d}$ and $N_{a}$ are the donor and acceptor densities respectively, $E$ is the applied potential, $E_{f b}$ is the flat band potential, $K$ is Boltzmann constant 
$\left(1.38 \times 10^{-23} \mathrm{JK}^{-1}\right), T$ is the absolute temperature, and $e$ is the elementary charge $\left(1.602 \times 10^{-19}\right.$ C).

The MS curves for A5 and A20 in $0.6 \mathrm{M} \mathrm{NaCl}$ solution are shown in Fig. 7. The positive slope indicates an n-type semiconductor behavior for both alloys [60]. The donor densities (slope of the fitting straight line) and flat band potential (intersection of the straight line with the potential axis) are shown in Fig. 7. For an $n$-type semiconductor, the donors are usually positive point defects such as oxygen vacancies or cation interstitials [57]. By increasing Mn concentration, the donor density is decreased from $2.66 \times 10^{17} \pm 1.96 \times 10^{16} \mathrm{~cm}^{-3}$ for A5 to $5.63 \times 10^{13} \pm 2.70$ $\left.X 10^{13}\right) \mathrm{cm}^{-3}$ for $A 20$. Moreover, the $E_{\mathrm{fb}}$ was shifted towards more negative values, $-320 \pm 27.8$ $\mathrm{mV}$ and $-650 \pm 41.6 \mathrm{mV}$ for $\mathrm{A} 5$ and $\mathrm{A} 20$ respectively. The more positive $\mathrm{E}_{\mathrm{fb}}$ of $\mathrm{A} 5$ results from the adsorption of oxygen into the passive film as a result of the oxygen reduction cathodic reaction [61]. The decreased carrier densities of amorphous compared to crystalline alloy was similar to that reported elsewhere [56, 62]. The enhanced corrosion resistance of A20 could be explained by the point defect model [63], where the low concentration of cation vacancies retards the breakdown of the passive film when the $\mathrm{Cl}^{-}$are incorporated in the anion cites [33]. Taken all the results together, in chloride containing solutions, higher Mn concentration favors the formation of a thicker, more compact and protective passive film on the surface that significantly enhances the pitting resistance and lowers the corrosion rate of Al-Mn.

\subsection{Tribocorrosion behavior}

\subsubsection{Tribocorrosion tests at OCP}

Fig. 8 shows typical evolution of $E_{\mathrm{OC}}$ during tribocorrosion tests for all samples subjected to 0.5 $\mathrm{N}$ load in $0.6 \mathrm{M} \mathrm{NaCl}$ aqueous solution. It can be seen that once the normal load was applied, a shift of $E_{O C}$ towards more negative values was observed in all samples. This negative shift of potential could be related to the deterioration of the passive film and the exposure of newly depassivated areas (anode) having lower equilibrium potential compared to the rest passive

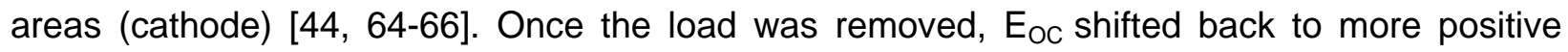
values towards its original state, indicating the recovery (repassivation) of the passive film. The amorphous alloy A20 exhibited the lowest negative shift (-20 $\pm 4 \mathrm{mV}$ vs. $\left.\mathrm{E}_{\mathrm{OC}}\right)$ and the highest recovery rate of $E_{O C}$ compared to $A 5\left(-250 \pm 42 \mathrm{mV} E_{O C}\right)$ and pure $A l\left(-400 \pm 31 \mathrm{mV} E_{O C}\right)$. During sliding, there is a competition between passive film removal and repassivation until a steady-state tribolayer forms in the worn area. The negligible negative shift of $E_{O C}$ for A20 thus suggests that the depassivation and repassivation rates were close to equilibrium for the amorphous alloy [67].

To gain better understanding of the depassivation-repassivation kinetics, a galvanic model proposed by Vieira et.al [64] was used to simulate the potential evolution during sliding. The cathodic potential $\left(E_{c}\right)$, i.e. potential of the passive areas, mainly depends on the anodic current and the anode to cathode area ratio. $E_{c}$ can be calculated as

$$
E_{c}=E_{c o r r}+a_{c}-b_{c} \log i_{a}-b_{c} \log \left[\left(\frac{1}{A_{\text {owt }}}\right)\left(\frac{L^{2} R C_{w} t}{0.0833}\right)^{0.333}\right],
$$

where $E_{\text {corr }}$ is the corrosion potential estimated from PD tests, $a_{c}$ and $b_{c}$ are the Tafel constants obtained from the linear regression of the cathodic part of PD curves, $i_{a}$ is the current density 
required to repassivate the worn areas, $A_{\text {owt }}$ is the area outside the wear track (estimated as the sample surface area exposed to the corrosive environment), $L$ is the wear track length, $R$ is the radius of the alumina ball, $\mathrm{C}_{\mathrm{w}}$ is a constant obtained by dividing the wear track volume by the sliding duration, and $t$ is the sliding time. The parameters used for Eqn. 6 are listed in Table 2 and the results for pure $A l$ and $A 5$ are shown in Fig.9. The fitted $i_{a}$ for $A 5\left(0.9 \pm 0.36 \mu A / \mathrm{cm}^{2}\right)$ is more than 10 times lower than that of pure Al $\left(13 \pm 4.6 \mu \mathrm{A} / \mathrm{cm}^{2}\right)$, indicating that less current density is required to repassivate the worn surface of A5. Given the similar depassivation rate imposed by mechanical wear, these results indicate a much faster repassivation rate of A5. It is also noted here that it was not possible to fit the $E_{C}$ evolution of $A 20$ with this model due to its very small change $(\sim 20 \mathrm{mV})$ over time. During tribocorrosion of $A 20$, it is estimated that $\sim 8 \mathrm{~nm}$ of the material is removed at the surface after each stroke, much larger than the passive film thickness ( $1.2 \mathrm{~nm}$ ), suggesting an even fast repassivation kinetics than A5 at higher Mn\%.

\subsubsection{Effects of applied potential}

The applied potential has often been found to significantly affect tribocorrosion resistance by accelerating the total material loss at anodic potentials $[68,69]$. In this study, the tribocorrosion behavior was evaluated at three potentials: $E_{O C}$, anodic (200 mV above $\left.E_{O C}\right)$ and cathodic (350 $\mathrm{mV}$ below $\mathrm{E}_{\mathrm{OC}}$ ) potential. The results are summarized in Fig. 10. The total material loss rate (i.e. volume loss normalized by sliding distance) was found to be lowest at the cathodic potential where the material removal was mainly caused by mechanical wear, and highest at the anodic potential due to the contribution of both corrosion and wear. This behavior is similar to that reported for heat treated Al alloy [64], 316L stainless steel [69] and tungsten [70] during tribocorrosion. Overall A20 exhibited the lowest material loss compared to A5 and pure Al at all applied potentials, which could be related to its high hardness and enhanced electrochemical properties, as discussed in sections 3.1 and 3.2. Fig. 10 (b) shows the evolution of coefficient of friction (COF) at various potentials. For pure Al and A5, COF was found to be almost insensitive to the applied potential while for A20, the anodic shift of applied potential led to a decrease of COF.

\subsubsection{Wear track morphology}

SEM images in Fig. 11 show the surface morphology of wear tracks after tribocorrosion tests at various applied potentials. Cross-sectional SEM images (not shown here) confirm that all wear track depths were less than the total film thickness and no film delamination was observed. At all potentials studied here, the wear track is characterized by scratches and grooves, indicating extensive abrasive wear. At a given potential, the wear track width decreases with increasing Mn content, indicating improved wear resistance at higher $\mathrm{Mn} \%$. At the anodic potential, no pit was observed for either A5 or A20. This is likely due to the high depassivation rate at the testing speed $(5 \mathrm{~mm} / \mathrm{s})$ that leads to active corrosion of the whole wear track. EDS maps of the wear tracks after tribocorrosion at the anodic potential are shown in Fig. 12. Mn distribution in both alloys was still uniform after tribocorrosion tests and no variation at the worn and unworn areas was detected. On the other hand, high oxygen content can be seen on the whole wear track of A5, most likely from trapped wear debris with high oxygen content. The fact that the oxygen 
distribution is patchy on A20 is consistent with its narrow and 'clean' wear track morphology, indicating milder wear compared to A5.

\subsubsection{Wear-corrosion synergy}

Passive metals often suffer from high wear-corrosion synergy, as discussed in the introduction. The wear-corrosion synergy (S) can be estimated as [44, 71]

$$
\mathrm{S}=\mathrm{T}-\mathrm{W}_{0}-\mathrm{C}_{0}
$$

where $T$ is the total material loss measured at $E_{O C}, W_{0}$ is the material loss measured at the cathodic potential primarily due to mechanical wear (where corrosion becomes negligible compared to wear), and $\mathrm{C}_{0}$ is the material loss due to pure corrosion estimated from PD tests [8, 72]. To be consistent with unit, all the terms in eqn. (7) was represented in $\mathrm{mm} / \mathrm{year}$. The synergy factor $(F)$ is defined as [73]:

$$
\mathrm{F}=\frac{\mathrm{T}}{(\mathrm{T}-\mathrm{S})}
$$

A high $\mathrm{F}$ value thus indicates high synergy between wear and corrosion. The results are shown in Fig. 13. Interestingly, even though $A 20$ exhibits lower $T, W_{0}$, and $C_{0}$, its wear-corrosion synergy is higher than A5. In other words, the combined attack of wear and corrosion is more detrimental to A20. In addition, it can be seen that under the testing conditions studied here, the total material loss is dominated by mechanical wear while corrosion is negligible. This is in agreement with the criteria proposed by Stack et.al, which take in consideration the ratio of chemical to mechanical wear $\left(C_{0} / W_{0}\right)$ [74-76]. For $C_{0} / W_{0} \leq 0.1$, wear is the dominating mechanism; for $0.1<C_{0} / W_{0} \leq 10$, both wear and corrosion contribute significantly to material degradation; and for $C_{0} / W_{0}>10$, corrosion is the dominating mechanism. In this work, $\mathrm{C}_{0} / \mathrm{W}_{0}$ is $2.33 \times 10^{-5}$ and $6.36 \times 10^{-5}$ for $\mathrm{A} 5$ and $\mathrm{A} 20$, respectively, well below 0.1 .

The origin of wear-corrosion synergy often comes from two terms: corrosion-accelerated wear and wear-accelerated corrosion [6]. For corrosion-accelerated wear, the excess material loss at OCP and anodic potential compared to the cathodic potential indicates that corrosion significantly accelerated wear of Al-Mn, most likely by trapping abrasive wear debris with high $\mathrm{Al}_{2} \mathrm{O}_{3}$ content. Wear debris particles generated at the presence of passive film are likely to contain higher oxygen content compared to those from wear tests without corrosion. Indeed, EDS analysis at the anodic potential shows a high oxygen concentration on the wear track of both samples (Fig. 12). Depending on the lubricity, these debris can act either as abrasive particles or solid lubricant. According to Erdemir's crystal chemical model [40], the lubricity of oxide is related to its ionic potential $\varphi=Z / r$, where $Z$ and $r$ is the charge and radius of the cation respectively. Oxides with high ionic potential $\varphi>7$ (such as $\mathrm{V}_{2} \mathrm{O}_{5}, \mathrm{MoO}_{3}$ ) are soft and lubricious, while oxides with low ionic potential $\varphi<7$ (such as $\mathrm{TiO}_{2}, \mathrm{Fe}_{2} \mathrm{O}_{3}$ ) are strong and difficult to shear. The ionic potential of $\mathrm{Al}_{2} \mathrm{O}_{3}$ is 4.4; thus, it is considered strong and abrasive and will lead to accelerated wear. It should also be noted that while manganese oxides such as $\mathrm{Mn}_{2} \mathrm{O}_{7}$ and $\mathrm{MnO}_{3}$ are lubricous, X-ray photoelectron spectroscopy study showed that the passive film of Al- 
$\mathrm{Mn}$ in $\mathrm{NaCl}$ aqueous solution was mainly consists of $\mathrm{AlO}(\mathrm{OH})$ and $\mathrm{Mn}$ was selectively dissolved in the exterior part of the oxide film [77]. Thus their effect on surface friction and wear can be neglected here.

In addition to corrosion-accelerated wear, another origin of wear-corrosion synergy is wearaccelerated corrosion, which can be measured by recording the current evolution under imposed passive potential $[6,7]$. Typically at the onset of rubbing, the wear track depassivates, leading to an increase in the current flow through the metal/electrolyte interface in order to sustain the imposed passive potential. As long as depassivation prevails during the test (I.e. the depassivation rate is much higher than repassivation rate), the current remains at an elevated level until the end of the test, when the current restores its original value due to subsequent repassivation of the anodic area. The current associated with the wear accelerated corrosion can then be quantified by calculating the total charge transferred due to this excess current flow. The evolution of this current for A5 and A20 at the anodic potential is shown in Fig. 14 (a). Before the initiation of sliding, both samples were in their passive states and the current is less than $1 \mu \mathrm{A}$. Unlike A5, which exhibit a sharp increase in current at the onset of rubbing, A20 exhibits a low current for the first $\sim 50 \mathrm{sec}$ before reaching steady state. It is likely that the high hardness of $A 20$ results in a smaller wear track during the initial running-in period, which can be repassivated quickly. During sliding, the current increase is higher in A5 than A20, indicating accelerated corrosion due to the deterioration of the passive film is more significant for the former $[8,78]$. Once the load was removed, the galvanic current shifted back towards its original state indicating the recovery of the passive film, similar to that reported in other passive alloys $[67,69,79,80]$.

To quantify the wear-accelerated corrosion, the contribution of electrochemical material loss $\left(\mathrm{V}_{\text {chem }}\right)$ resulted from metal oxidation under anodic applied potential could be calculated by Faraday's law as $[64,81,82]$

$$
\mathrm{V}_{\text {chem }}=\frac{Q M}{n F \rho},
$$

where $Q$ is the electrical charge (calculated by multiplying the difference between the average anodic current during and before sliding by the time), $\mathrm{M}$ is the molecular weight of $\mathrm{Al}$ (26.98 $\mathrm{g} / \mathrm{mole}$ ), $\mathrm{n}$ is the oxidation valence ( 3 for $\mathrm{Al}$ ), $\mathrm{F}$ is Faraday's constant $(96,500 \mathrm{C} / \mathrm{mole}$ ) and $\rho$ is the density $\left(\approx 2.7 \mathrm{~g} / \mathrm{cm}^{3}\right)$. The electrochemical material loss is equal to that required to repassivate the worn area (hence rebuild the oxide film) by metal oxidation [81]. The total material loss at the anodic potential is then represented by the sum of the electrochemical $\left(V_{\text {chem }}\right)$ and mechanical material loss $\left(\mathrm{V}_{\text {mech }}\right)$, as shown in Fig.14(b). It can be seen that $A 20$ exhibited less contribution of $\mathrm{V}_{\text {chem }}\left(8.3 \times 10^{-11} \pm 2.8 \times 10^{-13} \mathrm{~mm}^{3}\right)$ compared to $\mathrm{A} 5\left(1.9 \times 10^{-10} \pm 5.6 \times 10^{-11}\right.$ $\mathrm{mm}^{3}$ ), indicating less metal oxidation was required for repassivation at higher Mn\%. Mischler and Muñoz [83] showed that the wear-accelerated corrosion current is mainly a function of contact geometry and passivation charge density, the latter of which depends on the electrochemical conditions established within the contact and is kept constant under the same anodic potential for A5 and A20. During tribocorrosion, the Hertzian elastic contact from the alumina ball counter body sliding on the flat sample surface produces a macroscopic contact area that increases with decreasing effective elastic modulus [84]. Depassivation then occurs 
via plastic deformation of multiple microscopic asperities contacting the counter body within the hertzian contact area. Although the exact number of contacting asperities was difficult to estimate/measure, the smaller Hertzian contact area at higher $\mathrm{Mn} \%$ due to its increased elastic modulus (Section 3.1) is likely to result in a smaller real contact area (number of asperity contact times the contact size of each asperity), which eventually lead to the smaller $\mathrm{V}_{\text {chem. }}$.

\section{Summary and conclusions}

The main objective of this work was to study the effect of $\mathrm{Mn}$ addition on the tribocorrosion resistance of Al-Mn supersaturated solid solutions. Al and Al-Mn with 5.2 at.\% and 20.5 at.\% Mn were synthesized by magnetron sputtering. The role of $\mathrm{Mn}$ concentration and microstructure on the corrosion and tribocorrosion resistance of $\mathrm{Al}$ were evaluated in $3.5 \mathrm{wt} . \% \mathrm{NaCl}$ aqueous solution. Based on the combined tribological and electrochemical studies, the following conclusions were obtained:

(1) Increasing Mn concentration led to the formation of nanocrystalline (5.2 at.\% Mn) and fully amorphous (20.5 at.\% Mn) microstructures.

(2) Alloying Al with proper amount of $\mathrm{Mn}$ was found to significantly improve the wear, corrosion, and tribocorrosion resistance of $\mathrm{Al}$.

(3) Mn addition increased the hardness of Al by solid solution strengthening and structure refinement. Such hardness increment resulted in improved wear and tribocorrosion resistance.

(4) Mn addition enhanced the protectiveness of passive film; thicker and denser passive film with lower defect density was formed at higher Mn concentration.

(5) The total material loss during tribocorrosion of Al-Mn was found to increase with applied potential. At cathodic potentials, mechanical wear dominates tribocorrosion, and the total material loss is mainly governed by the mechanical properties of the material. At open circuit and anodic potentials, mechanical wear led to local depassivation of the wear track, with the ensuring active corrosion resulting in accelerated material loss.

(6) Finally, the Al-Mn system studied here is self-repairing; upon the removal of mechanical load, the depassivated area quickly repassivates, with faster repassivation kinetics at higher Mn content.

\section{Acknowledgements}

This research was financially supported by the National Science Foundation under Grant DMR1455108. Materials preparation and characterization were conducted at the Nano Research and Educational Center (NREC) at the University of South Florida. The authors thankfully acknowledge the discussion with Dr. Alberto A. Sagüés at the University of South Florida. 


\section{References}

1. ASTM G40-10b, Standard Terminology Relating to Wear and Erosion. Annual Book of ASTM Standards. Vol. 03.02. 2010, West Conshohocken, PA: ASTM International.

2. Landolt, D. and S. Mischler, Tribocorrosion of passive metals and coatings. Vol. No 47. 2011, EPFL, Switzerland: Woodhead Publishing Series in Metals and Surface Engineering.

3. Macdonald, D.D., Passivity - the key to our metals-based civilization. Pure and Applied Chemistry, 1999. 71(6): p. 951-978.

4. Mischler, S., Sliding Tribo-Corrosion of Passive Metals: Mechanisms and Modeling, in TriboCorrosion: Research, Testing, and Applications, J.-P. Peter J. Blau and a.D.D. Celis, Editors. 2013, ASTM International: Atlanta, GA. p. 1-18.

5. Pokhmurs'kyi, V.I. and V.M. Dovhunyk, Tribocorrosion of Stainless Steels (Review). Materials Science, 2010. 46(1): p. 87-96.

6. Landolt, D., S. Mischler, and M. Stemp, Electrochemical methods in tribocorrosion: a critical appraisal. Electrochimica Acta, 2001. 46(24-25): p. 3913-3929.

7. Landolt, D., Electrochemical and materials aspects of tribocorrosion systems. Journal of Physics D-Applied Physics, 2006. 39(15): p. 3121-3127.

8. Watson, S.W., F.J. Friedersdorf, B.W. Madsen, and S.D. Cramer, Methods of measuring wearcorrosion synergism. Wear, 1995. 181: p. 476-484.

9. Williams, J.A., Engineering tribology. 1994: Oxford ; New York : Oxford University Press, 1994.

10. Jemmely, P., S. Mischler, and D. Landolt, Electrochemical modeling of passivation phenomena in tribocorrosion. Wear, 2000. 237(1): p. 63-76.

11. Vargel, C., Corrosion of Aluminium. 2004 Elsevier Science.

12. Caporali, S., A. Fossati, A. Lavacchi, I. Perissi, A. Tolstogouzov, and U. Bardi, Aluminium electroplated from ionic liquids as protective coating against steel corrosion. Corrosion Science, 2008. 50(2): p. 534-539.

13. Wu, G., X. Zeng, and G. Yuan, Growth and corrosion of aluminum PVD-coating on AZ31 magnesium alloy. Materials Letters, 2008. 62(28): p. 4325-4327.

14. Mao, S., H. Yang, J. Li, F. Huang, and Z. Song, Corrosion properties of aluminium coatings deposited on sintered NdFeB by ion-beam-assisted deposition. Applied Surface Science, 2011. 257(13): p. 5581-5585.

15. Archard, J.F., Contact and rubbing of flat surfaces. Journal of Applied Physics, 1953. 24(8): p. 981-988.

16. Rupert, T.J., W.J. Cai, and C.A. Schuh, Abrasive wear response of nanocrystalline Ni-W alloys across the Hall-Petch breakdown. Wear, 2013. 298: p. 120-126.

17. Kim, Y. and R.G. Buchheit, A characterization of the inhibiting effect of $\mathrm{C} U$ on metastable pitting in dilute Al-Cu solid solution alloys. Electrochimica Acta, 2007. 52(7): p. 2437-2446.

18. Kim, Y., R.G. Buchheit, and P.G. Kotula, Effect of alloyed Cu on localized corrosion susceptibility of Al-Cu solid solution alloys-Surface characterization by XPS and STEM. Electrochimica Acta, 2010. 55(24): p. 7367-7375.

19. Sanchette, F., C. Ducros, A. Billard, C. Rebere, C. Berziou, M. Reffass, and J. Creus, Nanostructured aluminium based coatings deposited by electron-beam evaporative PVD. Thin Solid Films, 2009. 518(5): p. 1575-1580.

20. Merl, D.K., P. Panjan, and I. Milosev, Effect of tungsten content on properties of PVD sputtered Al-W-X alloys. Surface Engineering, 2013. 29(4): p. 281-286.

21. Chuang, M.-H., M.-H. Tsai, W.-R. Wang, S.-J. Lin, and J.-W. Yeh, Microstructure and wear behavior of AlxCo1.5CrFeNi1.5Tiy high-entropy alloys. Acta Materialia, 2011. 59(16): p. 63086317. 
22. Wu, J.-M., S.-J. Lin, J.-W. Yeh, S.-K. Chen, Y.-S. Huang, and H.-C. Chen, Adhesive wear behavior of AlxCoCrCuFeNi high-entropy alloys as a function of aluminum content. Wear, 2006. 261(5-6): p. 513-519.

23. Lin, C.-M. and H.-L. Tsai, Evolution of microstructure, hardness, and corrosion properties of highentropy AlO.5CoCrFeNi alloy. Intermetallics, 2011. 19(3): p. 288-294.

24. Mraied, H., W.J. Cai, and A.A. Sagüés, Corrosion resistance of $A l$ and Al-Mn thin films. Thin Solid Films, 2016. 615: p. 391-401.

25. Ruan, S. and C.A. Schuh, Electrodeposited Al-Mn alloys with microcrystalline, nanocrystalline, amorphous and nano-quasicrystalline structures. Acta Materialia, 2009. 57(13): p. 3810-3822.

26. Kek Merl, D., P. Panjan, and J. Kovač, Corrosion and surface study of sputtered Al-W coatings with a range of tungsten contents. Corrosion Science, 2013. 69: p. 359-368.

27. Creus, J., A. Billard, and F. Sanchette, Corrosion behaviour of amorphous Al-Cr and Al-Cr-(N) coatings deposited by dc magnetron sputtering on mild steel substrate. Thin Solid Films, 2004. 466(1-2): p. 1-9.

28. Creus, J., C. Berziou, S. Cohendoz, A. Perez, C. Rebere, M. Reffass, S. Touzain, C. Allely, Y. Gachon, C. Heau, F. Sanchette, and A. Billard, Reactivity classification in saline solution of magnetron sputtered or EBPVD pure metallic, nitride and Al-based alloy coatings. Corrosion Science, 2012. 57: p. 162-173.

29. Perez, A., A. Billard, C. Rébéré, C. Berziou, S. Touzain, and J. Creus, Influence of metallurgical states on the corrosion behaviour of Al-Zn PVD coatings in saline solution. Corrosion Science, 2013. 74: p. 240-249.

30. Bielawski, M., Development of unbalanced magnetron sputtered Al-Mo coatings for cadmium replacement. Surface and Coatings Technology, 2004. 179(1): p. 10-17.

31. Frankel, G.S., M.A. Russak, C.V. Jahnes, M. Mirzamaani, and V.A. Brusic, Pitting of Sputtered Aluminum Alloy Thin Films. Journal of The Electrochemical Society, 1989. 136(4): p. 1243-1244.

32. Car, T., N. Radić, P. Panjan, M. Čekada, and A. Tonejc, Correlation between hardness and stress in Al-(Nb, Mo, Ta) thin films. Thin Solid Films, 2009. 517(16): p. 4605-4609.

33. Szklarska-Smialowska, Z., Pitting corrosion of aluminum. Corrosion Science, 1999. 41(9): p. 17431767.

34. Gudic, S., I. Smoljko, and M. Kliskic, The effect of small addition of tin and indium on the corrosion behavior of aluminium in chloride solution. Journal of Alloys and Compounds, 2010. 505(1): p. 54-63.

35. Reffass, M., C. Berziou, C. Rébéré, A. Billard, and J. Creus, Corrosion behaviour of magnetronsputtered Al1-x-Mnx coatings in neutral saline solution. Corrosion Science, 2010. 52(11): p. 3615-3623.

36. Frankel, G.S., R.C. Newman, C.V. Jahnes, and M.A. Russak, On the Pitting Resistance of SputterDeposited Aluminum-Alloys. Journal of the Electrochemical Society, 1993. 140(8): p. 2192-2197.

37. Moffat, T.P., G.R. Stafford, and D.E. Hall, Pitting Corrosion of Electrodeposited AluminumManaganese Alloys. Journal of the Electrochemical Society, 1993. 140(10): p. 2779-2786.

38. Murdoch, H.A. and C.A. Schuh, Estimation of grain boundary segregation enthalpy and its role in stable nanocrystalline alloy design. Journal of Materials Research, 2013. 28(16): p. 2154-2163.

39. Huang, T.-Y., C.J. Marvel, P.R. Cantwell, M.P. Harmer, and C.A. Schuh, Grain boundary segregation in Al-Mn electrodeposits prepared from ionic liquid. Journal of Materials Science, 2015. 51(1): p. 438-448.

40. Erdemir, A., A crystal chemical approach to the formulation of self-lubricating nanocomposite coatings. Surface and Coatings Technology, 2005. 200(5-6): p. 1792-1796. 
41. Murray, J.L., A.J. McAlister, R.J. Schaefer, L.A. Bendersky, F.S. Biancaniello, and D.L. Moffat, Stable and metastable phase equilibria in the Al-Mn system. Metallurgical Transactions A, 1987. 18(3): p. 385-392.

42. Grushko, B. and G. Stafford, Phase formation in electrodeposited and thermally annealed Al-Mn alloys. Metallurgical Transactions A, 1990. 21(11): p. 2869-2879.

43. Oliver, W.C. and G.M. Pharr, An improved technique for determining hardness and elastic modulus using load and displacement sensing indentation experiments. Journal of Materials Research, 1992. 7(06): p. 1564-1583.

44. Mischler, S., Triboelectrochemical techniques and interpretation methods in tribocorrosion: $A$ comparative evaluation. Tribology International, 2008. 41(7): p. 573-583.

45. Mraied, H., W.J. Cai, and A.A. Sagues, Corrosion resistance of Al and Al-Mn thin films. Thin Solid Films, 2016. 615: p. 391-401.

46. Cai, W.J. and C.A. Schuh, Tuning nanoscale grain size distribution in multilayered Al-Mn alloys. Scripta Materialia, 2012. 66(3-4): p. 194-197.

47. Wang, W.Y., K.A. Darling, Y. Wang, S.L. Shang, L.J. Kecskes, X.D. Hui, and Z.K. Liu, Power law scaled hardness of $\mathrm{Mn}$ strengthened nanocrystalline Al-Mn non-equilibrium solid solutions. Scripta Materialia, 2016. 120: p. 31-36.

48. Leyland, A. and A. Matthews, Design criteria for wear-resistant nanostructured and glassy-metal coatings. Surface and Coatings Technology, 2004. 177-178: p. 317-324.

49. Lekatou, A., A.K. Sfikas, C. Petsa, and A.E. Karantzalis, Al-Co Alloys Prepared by Vacuum Arc Melting: Correlating Microstructure Evolution and Aqueous Corrosion Behavior with Co Content. Metals, 2016. 6(3): p. 46.

50. Yan, J.F., N.M. Heckman, L. Velasco, and A.M. Hodge, Improve sensitization and corrosion resistance of an Al-Mg alloy by optimization of grain boundaries. Scientific Reports, 2016. 6.

51. Carranza, R.M. and J.R. Galvele, Repassivation Kinetics in Stress-Corrosion Cracking .1. Type Aisi304 Stainless-Steel in Chloride Solutions. Corrosion Science, 1988. 28(3): p. 233-249.

52. Akhoondan, M. and A.A. Sagüés, Corrosion Mechanism of Aluminized Steel in Limestone Backfill. Corrosion, 2013. 69(12): p. 1147-1157.

53. Li, L. and A.A. Sagüés, Chloride Corrosion Threshold of Reinforcing Steel in Alkaline SolutionsOpen-Circuit Immersion Tests. Corrosion, 2001. 57(1): p. 19-28.

54. González, J.A., V. López, A. Bautista, E. Otero, and X.R. Nóvoa, Characterization of porous aluminium oxide films from a.c. impedance measurements. Journal of Applied Electrochemistry, 1999. 29(2): p. 229-238.

55. Zhang, B., Y. Li, and F. Wang, Electrochemical corrosion behaviour of microcrystalline aluminium in acidic solutions. Corrosion Science, 2007. 49(5): p. 2071-2082.

56. Zhang, J., W. Zhang, C. Yan, K. Du, and F. Wang, Corrosion behaviors of Zn/Al-Mn alloy composite coatings deposited on magnesium alloy AZ31B (Mg-Al-Zn). Electrochimica Acta, 2009. 55(2): p. 560-571.

57. Martin, F.J., G.T. Cheek, W.E. O'Grady, and P.M. Natishan, Impedance studies of the passive film on aluminium. Corrosion Science, 2005. 47(12): p. 3187-3201.

58. de Oliveira, M.C.L., V.S.M. Pereira, O.V. Correa, N.B. de Lima, and R.A. Antunes, Correlation between the corrosion resistance and the semiconducting properties of the oxide film formed on AZ91D alloy after solution treatment. Corrosion Science, 2013. 69: p. 311-321.

59. Jinlong, L. and L. Hongyun, Comparison of corrosion properties of passive films formed on phase reversion induced nano/ultrafine-grained 321 stainless steel. Applied Surface Science, 2013. 280: p. 124-131.

60. Bockris, J.O.M. and Y. Kang, The protectivity of aluminum and its alloys with transition metals. Journal of Solid State Electrochemistry, 1997. 1(1): p. 17-35. 
61. Azumi, K., T. Ohtsuka, and N. Sato, Mott - Schottky Plot of the Passive Film Formed on Iron in Neutral Borate and Phosphate Solutions. Journal of The Electrochemical Society, 1987. 134(6): p. 1352-1357.

62. Wang, D.P., S.L. Wang, and J.Q. Wang, Relationship between amorphous structure and corrosion behaviour in a Zr-Ni metallic glass. Corrosion Science, 2012. 59: p. 88-95.

63. Chao, C.Y., L.F. Lin, and D.D. Macdonald, A Point Defect Model for Anodic Passive Films: I . Film Growth Kinetics. Journal of The Electrochemical Society, 1981. 128(6): p. 1187-1194.

64. Vieira, A.C., L.A. Rocha, N. Papageorgiou, and S. Mischler, Mechanical and electrochemical deterioration mechanisms in the tribocorrosion of $\mathrm{Al}$ alloys in $\mathrm{NaCl}$ and in $\mathrm{NaNO} 3$ solutions. Corrosion Science, 2012. 54: p. 26-35.

65. Ponthiaux, P., F. Wenger, D. Drees, and J.P. Celis, Electrochemical techniques for studying tribocorrosion processes. Wear, 2004. 256(5): p. 459-468.

66. Zhang, Y., X. Yin, J. Wang, and F. Yan, Influence of microstructure evolution on tribocorrosion of 304SS in artificial seawater. Corrosion Science, 2014. 88: p. 423-433.

67. Pina, V.G., A. Dalmau, F. Devesa, V. Amigó, and A.I. Muñoz, Tribocorrosion behavior of beta titanium biomedical alloys in phosphate buffer saline solution. Journal of the Mechanical Behavior of Biomedical Materials, 2015. 46: p. 59-68.

68. Papageorgiou, N. and S. Mischler, Electrochemical Simulation of the Current and Potential Response in Sliding Tribocorrosion. Tribology Letters, 2012. 48(3): p. 271-283.

69. Sun, Y. and E. Haruman, Effect of electrochemical potential on tribocorrosion behavior of low temperature plasma carburized 316L stainless steel in $1 \mathrm{M} \mathrm{H} 2 \mathrm{SO} 4$ solution. Surface and Coatings Technology, 2011. 205(17-18): p. 4280-4290.

70. Akonko, S.B., D.Y. Li, M. Ziomek-Moroz, J. Hawk, A. Miller, and K. Cadien, Effects of K3[Fe(CN)6] slurry's $\mathrm{pH}$ value and applied potential on tungsten removal rate for chemical-mechanical planarization application. Wear, 2005. 259(7-12): p. 1299-1307.

71. Tao, S. and D.Y. Li, Investigation of corrosion-wear synergistic attack on nanocrystalline $\mathrm{Cu}$ deposits. Wear, 2007. 263(1-6): p. 363-370.

72. Assi, F. and H. Böhni, Study of wear-corrosion synergy with a new microelectrochemical technique1. Wear, 1999. 233-235: p. 505-514.

73. Zhang, Y., X. Yin, J. Wang, and F. Yan, Influence of potentials on the tribocorrosion behavior of 304SS in artificial seawater. RSC Advances, 2014. 4(99): p. 55752-55759.

74. Stack, M.M. and K. Chi, Mapping sliding wear of steels in aqueous conditions. Wear, 2003. 255(1-6): p. 456-465.

75. Stack, M.M. and N. Pungwiwat, Erosion-corrosion mapping of Fe in aqueous slurries: some views on a new rationale for defining the erosion-corrosion interaction. Wear, 2004. 256(5): p. 565576.

76. Mathew, M.T., E. Ariza, L.A. Rocha, A.C. Fernandes, and F. Vaz, TiCxOy thin films for decorative applications: Tribocorrosion mechanisms and synergism. Tribology International, 2008. 41(7): p. 603-615.

77. Zhang, J.F., W. Zhang, C.W. Yan, K.Q. Du, and F.H. Wang, Corrosion behaviors of Zn/Al-Mn alloy composite coatings deposited on magnesium alloy AZ31B (Mg-Al-Zn). Electrochimica Acta, 2009. 55(2): p. 560-571.

78. Jiang, J., M.M. Stack, and A. Neville, Modelling the tribo-corrosion interaction in aqueous sliding conditions. Tribology International, 2002. 35(10): p. 669-679.

79. Priya, R., C. Mallika, and U.K. Mudali, Wear and tribocorrosion behaviour of 304L SS, Zr-702, Zircaloy-4 and Ti-grade2. Wear, 2014. 310(1-2): p. 90-100.

80. Stemp, M., S. Mischler, and D. Landolt, The effect of mechanical and electrochemical parameters on the tribocorrosion rate of stainless steel in sulphuric acid. Wear, 2003. 255(1-6): p. 466-475. 
81. Mischler, S., A. Spiegel, and D. Landolt, The role of passive oxide films on the degradation of steel in tribocorrosion systems. Wear, 1999. 225-229, Part 2: p. 1078-1087.

82. Mischler, S. and A.I. Muñoz, Wear of CoCrMo alloys used in metal-on-metal hip joints: $A$ tribocorrosion appraisal. Wear, 2013. 297(1-2): p. 1081-1094.

83. Mischler, S. and A.I. Munoz, Wear of CoCrMo alloys used in metal-on-metal hip joints: $A$ tribocorrosion appraisal. Wear, 2013. 297(1-2): p. 1081-1094.

84. Bowden, F.P. and D. Tabor, The area of contact between stationary and between moving surfaces. Proceedings of the Royal Society of London Series a-Mathematical and Physical Sciences, 1939. 169(938): p. 391-413. 
Table1. Summary of electrochemical parameters of Al and Al-Mn alloys obtained from PD tests in $0.6 \mathrm{M} \mathrm{NaCl}$ aqueous solution. All data is shown as average (range).

\begin{tabular}{c|c|c|c|c|c}
\hline $\begin{array}{c}\text { Sample } \\
\mathrm{ID}\end{array}$ & $\begin{array}{c}\mathrm{E}_{\mathrm{oc}} \\
(\mathrm{mV})\end{array}$ & $\begin{array}{c}\mathrm{E}_{\mathrm{pit}} \\
(\mathrm{mV})\end{array}$ & $\begin{array}{c}\text { Nominal } \mathrm{i}_{\mathrm{corr}} \\
\left(\mathrm{A} / \mathrm{cm}^{2}\right) \times 10^{-7}\end{array}$ & $\begin{array}{c}\beta_{\mathrm{a}} \\
(\mathrm{V} / \text { decade })\end{array}$ & $\begin{array}{c}\beta_{\mathrm{c}} \\
(\mathrm{V} / \text { decade })\end{array}$ \\
\hline Al & $-730(105)$ & $-640(12)$ & $8.3(3.0)$ & - & $0.75(0.17)$ \\
A5 & $-450(64)$ & $-276(16)$ & $0.9(0.3)$ & $0.23(0.17)$ & $0.23(0.10)$ \\
A20 & $-564(62)$ & $-110(54)$ & $0.8(0.4)$ & $0.35(0.05)$ & $0.31(0.26)$ \\
\hline
\end{tabular}

Table 2. Summary of parameters used to fit the cathodic potentials in Eqn. 6.

\begin{tabular}{ccccccccc}
\hline & $\mathrm{E}_{\text {corr }}(\mathrm{V})$ & $\mathrm{a}_{\mathrm{c}}$ & $\mathrm{b}_{\mathrm{c}}$ & $\mathrm{A}_{\text {owt }}\left(\mathrm{cm}^{2}\right)$ & $\mathrm{L}(\mathrm{cm})$ & $\mathrm{R}(\mathrm{cm})$ & $\mathrm{C}_{\mathrm{w}}\left(\mathrm{cm}^{3} / \mathrm{s}\right)$ & $\mathrm{T}(\mathrm{s})$ \\
\hline $\mathrm{Al}$ & -0.574 & -2.90 & 0.33 & 1.8 & 0.5 & 0.2 & $2.27 \times 10^{-9}$ & 300 \\
\hline A5 & -0.442 & -1.82 & 0.19 & 1.8 & 0.5 & 0.2 & $8.37 \times 10^{-10}$ & 300 \\
\hline
\end{tabular}


(a)

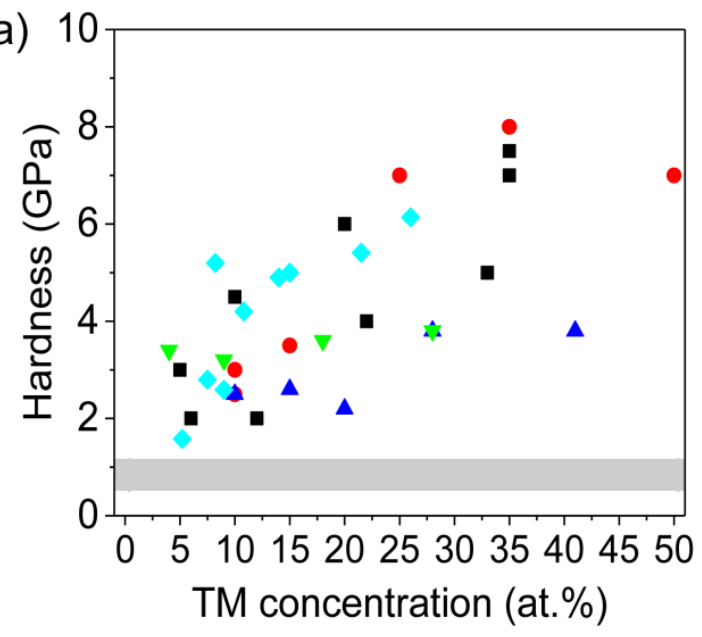

(c)

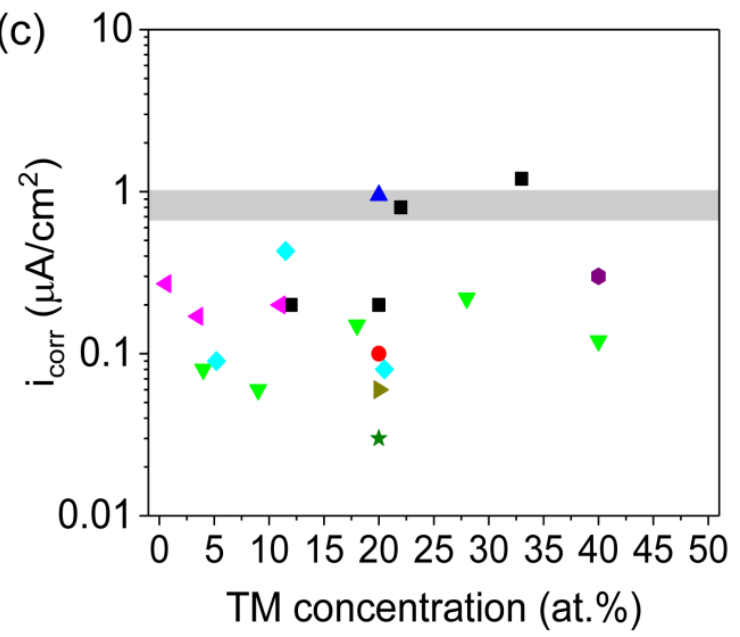

(b)

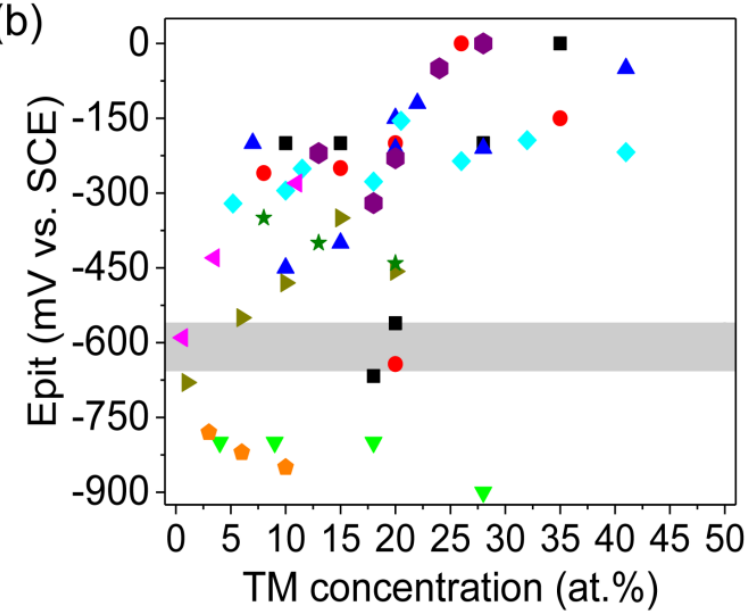

(d)

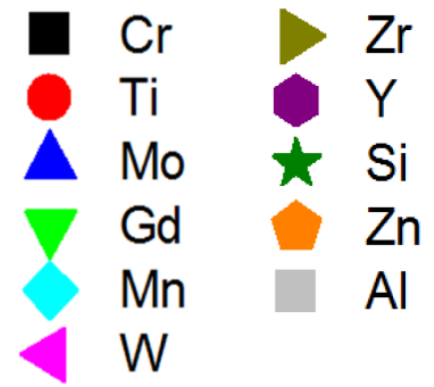

Figure 1. Summary of (a) hardness, (b) pitting potential, and (c) corrosion current density as a function of transition metal (TM) concentration in Al-TM systems [19, 24-32]. Data labels used in (a)-(c) are shown in (d). 


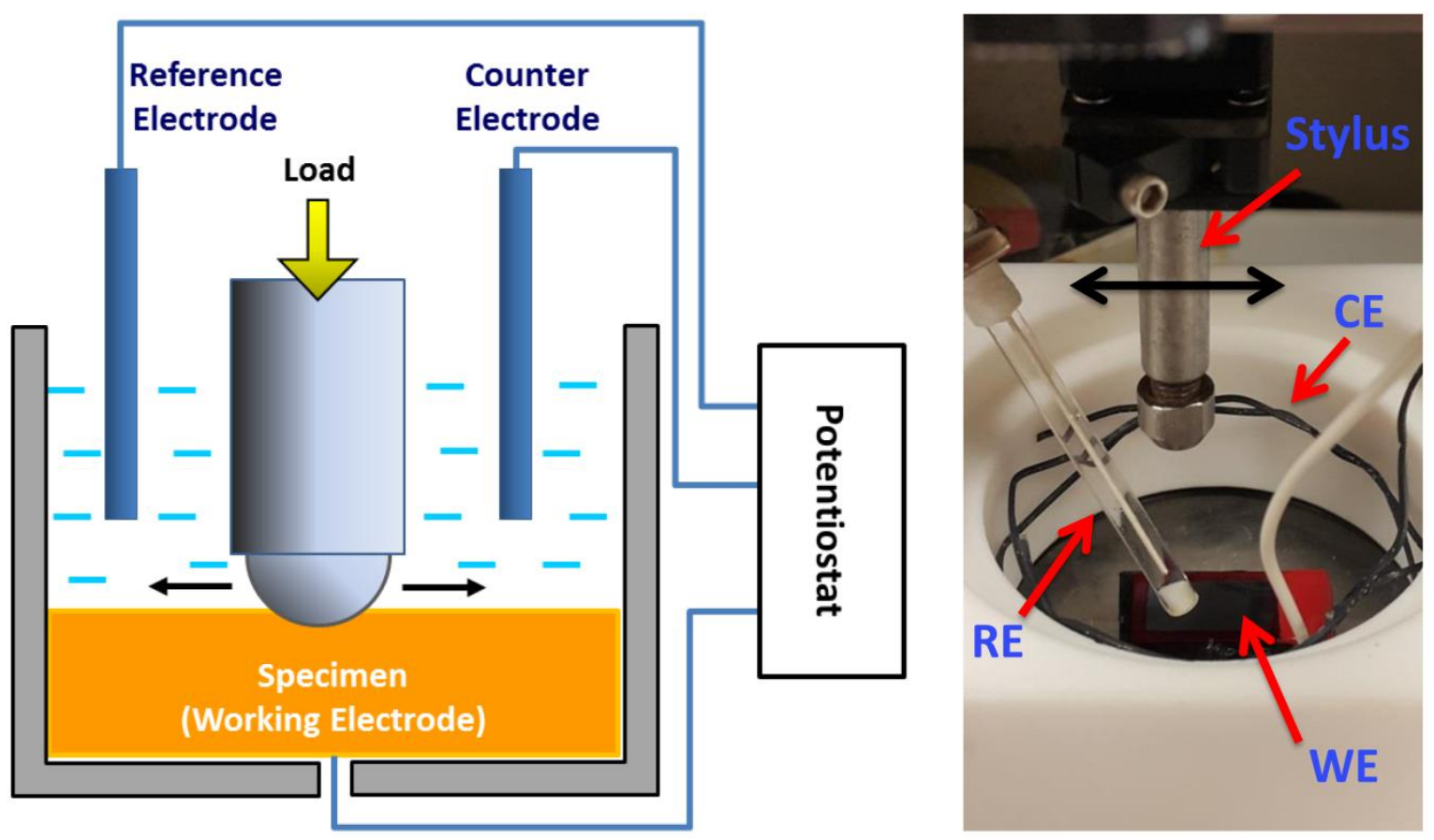

Figure 2. Schematic illustration (left) and photo (right) of tribocorrosion set-up used in the current study. 


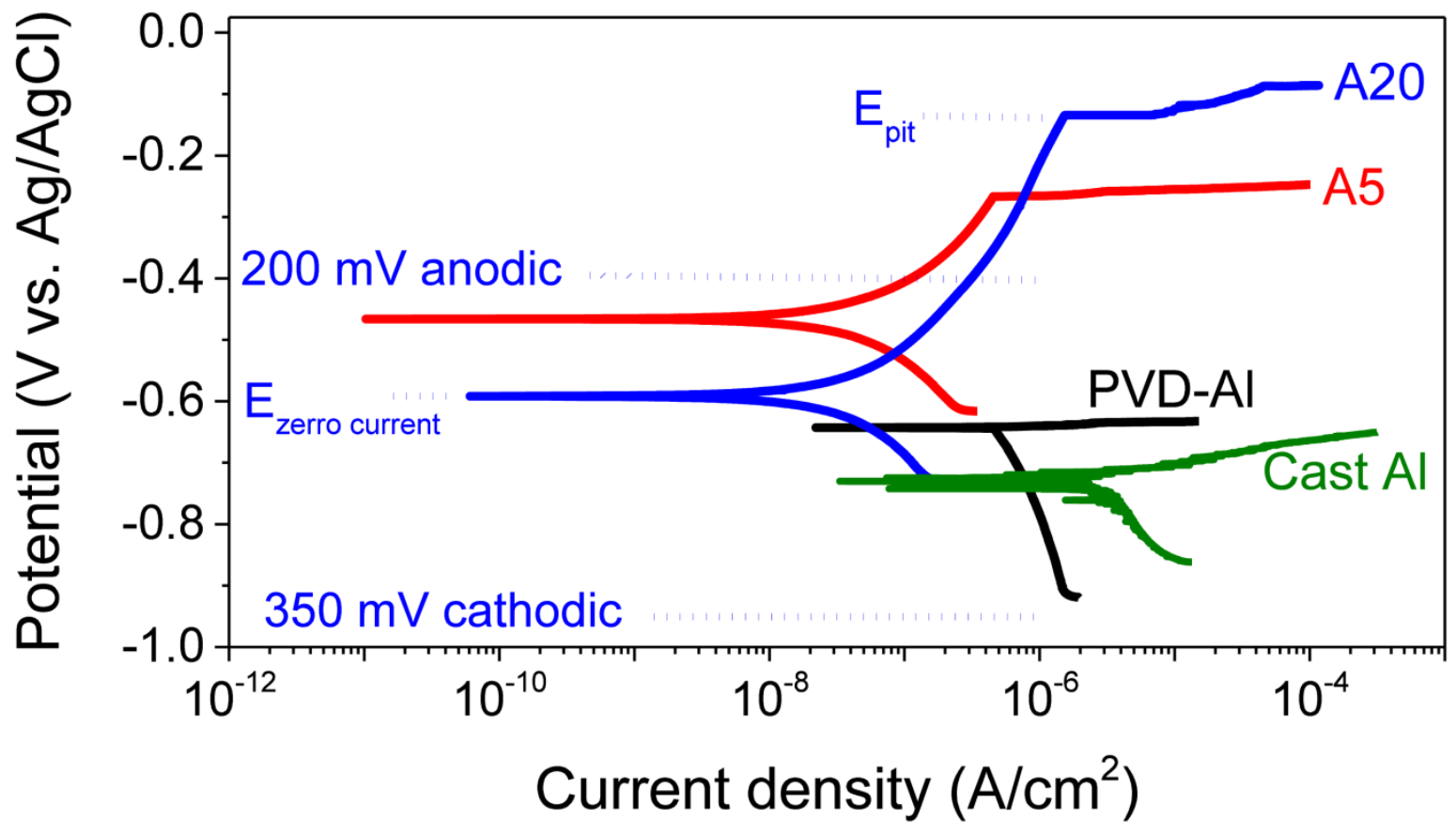

Figure 3. Typical potentiodynamic polarization curves of cast Al (99.99\%), PVD Al and Al-Mn alloys after 1 hour immersion in $0.6 \mathrm{M} \mathrm{NaCl}$ solution. 


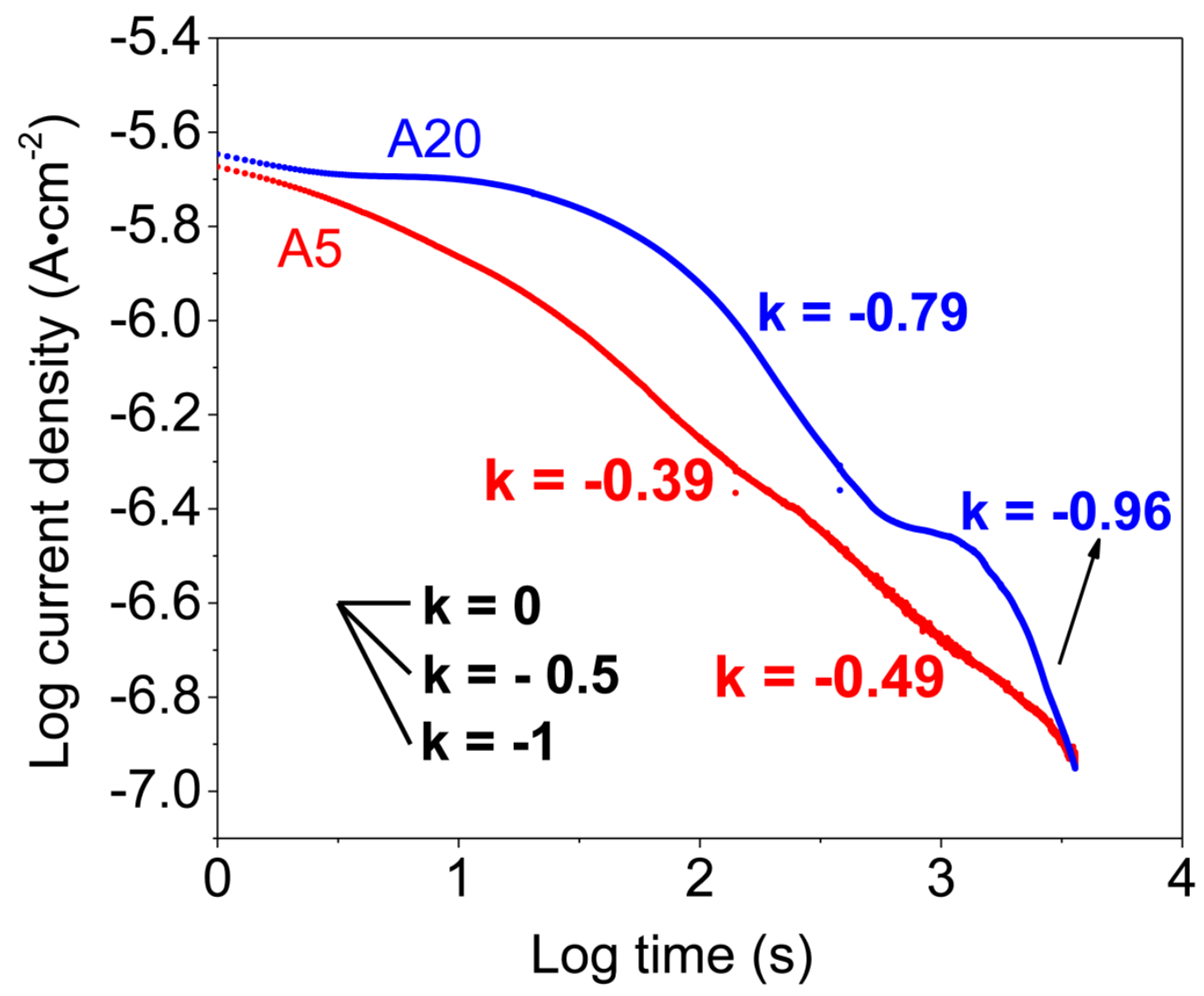

Figure 4. Double-log plots of current-time of the amorphous and crystalline Al-Mn alloys during anodic potentiostatic polarization at a constant potential of $200 \mathrm{mV}$ vs. their respective $E_{o c}$ for $3,600 \mathrm{~s}$ in $0.6 \mathrm{M} \mathrm{NaCl}$ aqueous solution. 


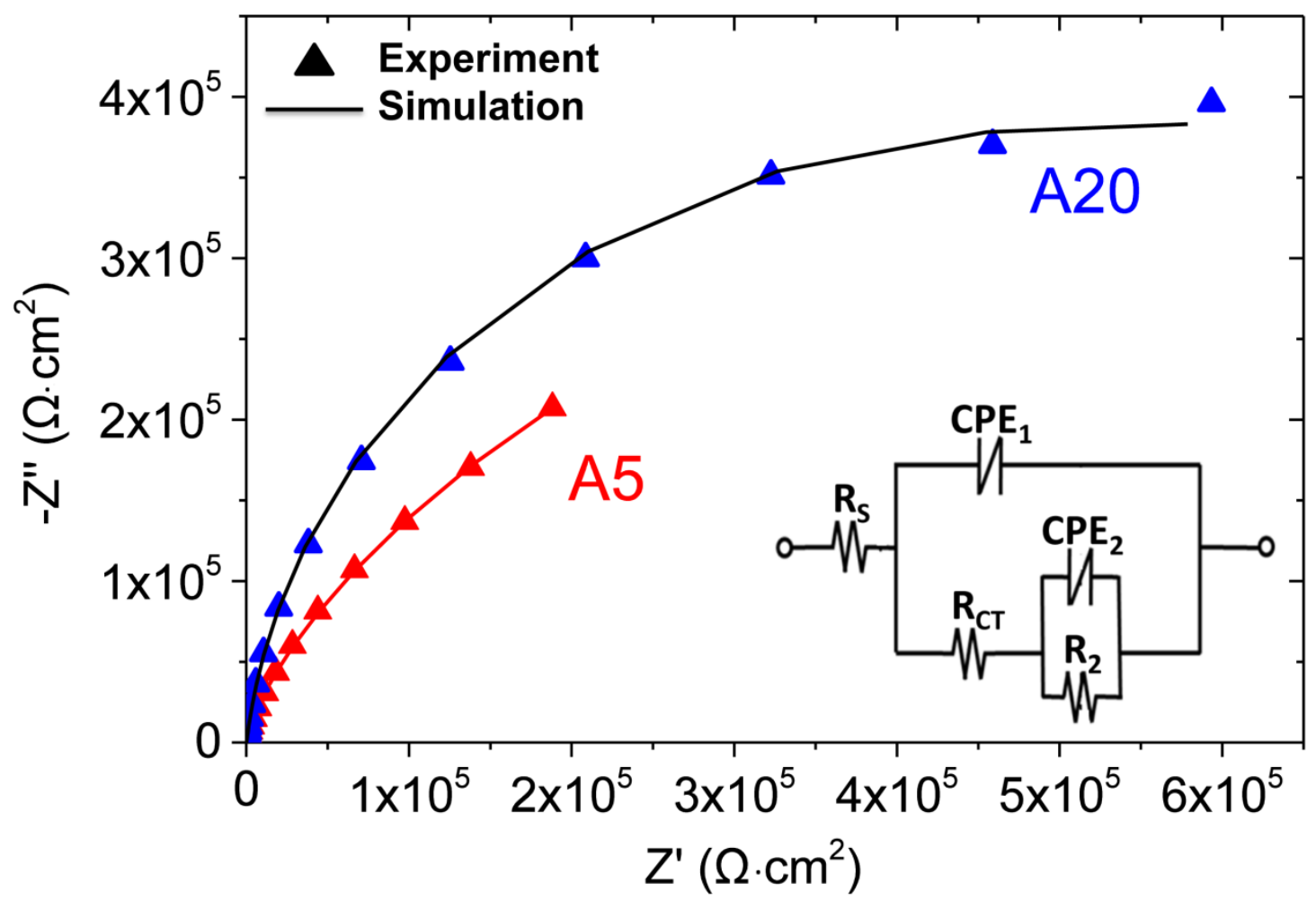

Figure 5. Typical Nyquist representation of EIS measurement (scattered data) and model fit (solid lines) of the amorphous and crystalline Al-Mn alloys measured at open circuit potential, 10 $\mathrm{mHz}$ minimum frequency at data collecting frequency of 5 points per decade. The average value of $\mathrm{E}_{\mathrm{OC}}$ is -461.4 and $-553.5 \mathrm{mV}$ vs. $\mathrm{Ag} / \mathrm{AgCl}$ for $\mathrm{A} 5$ and $\mathrm{A} 20$, respectively. 
(a)

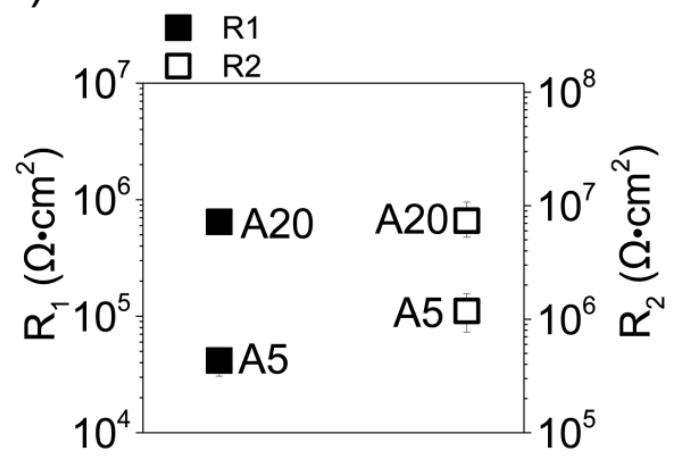

(c)

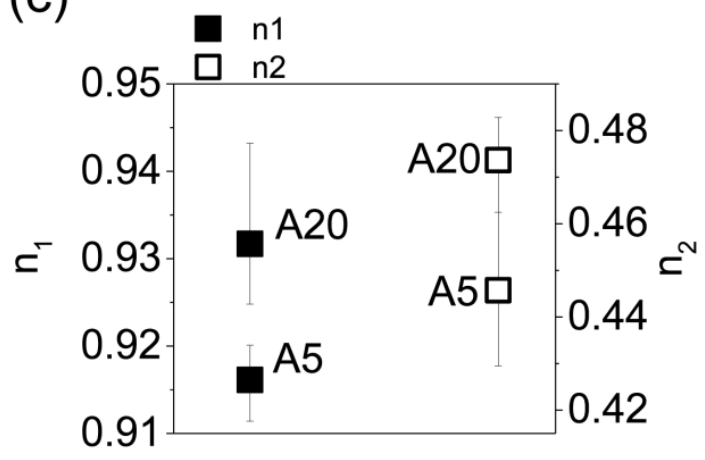

(b)

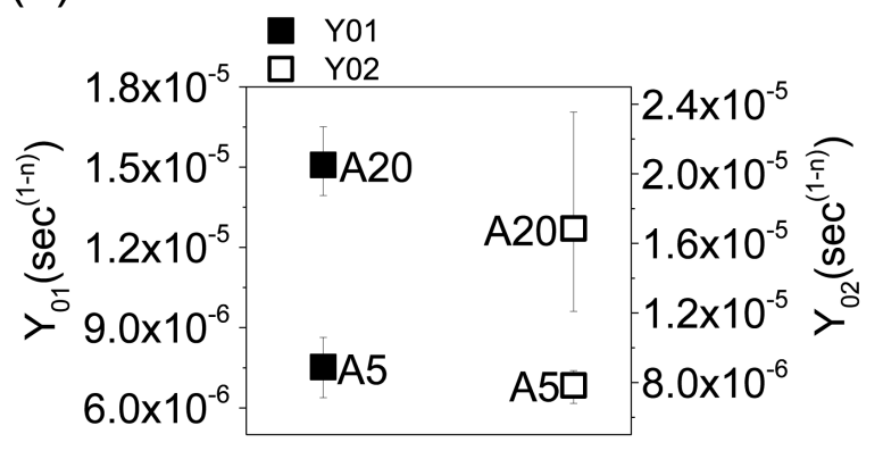

(d)

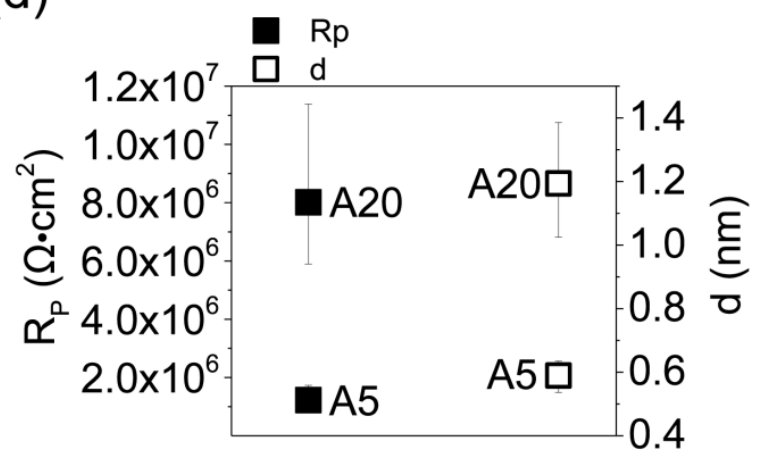

Figure 6. Equivalent circuit parameters (a) $R$, (b) $Y_{0}$, (c) $n$, and (d) $R_{P}$ and passive film thickness (d) of the amorphous (A20) and crystalline (A5) Al-Mn alloys in 0.6 M NaCl solution. 
(a)

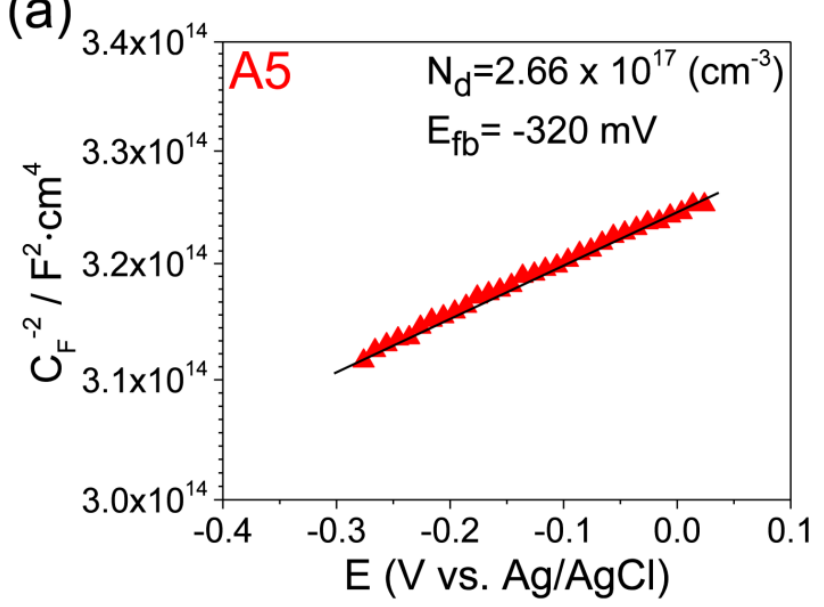

(b)

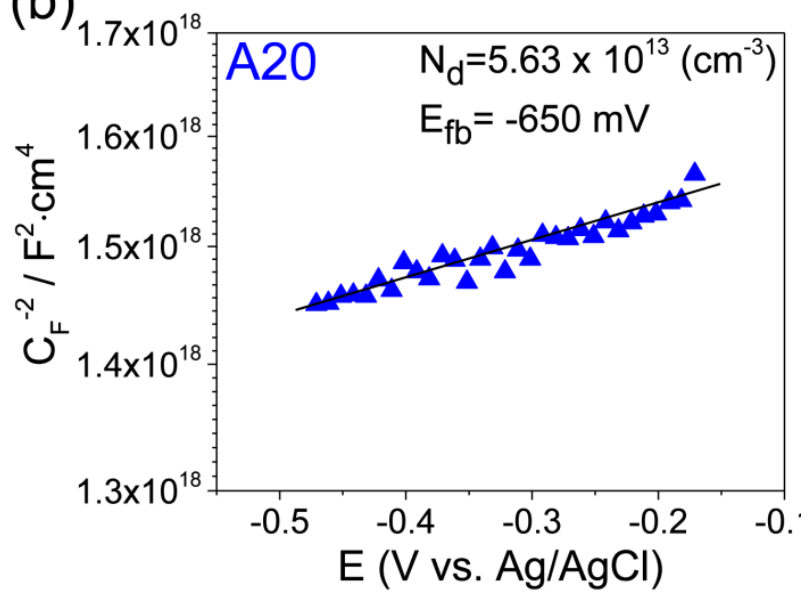

Figure 7. Mott-Schottky plots of passive films formed on the amorphous and crystalline Al-Mn alloys after anodic potentiostatic polarization in $0.6 \mathrm{M} \mathrm{NaCl}$ aqueous solutions with a measurement frequency of $1 \mathrm{kHz}$. The average value of $\mathrm{E}_{\mathrm{OC}}$ is -461.4 and $-553.5 \mathrm{mV}$ vs. $\mathrm{Ag} / \mathrm{AgCl}$ for $\mathrm{A} 5$ and $\mathrm{A} 20$, respectively. 


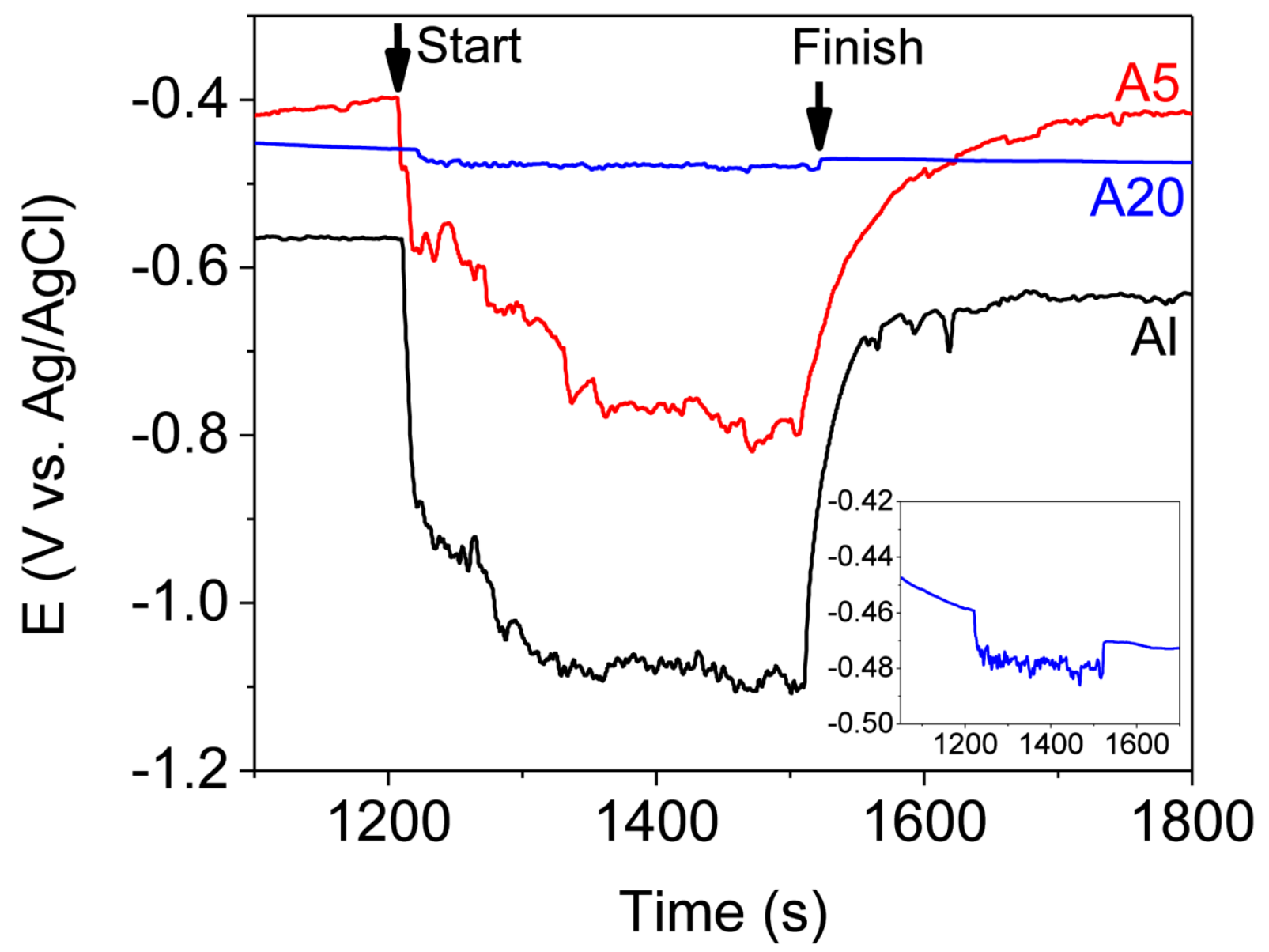

Figure 8. Evolution of corrosion potential before, during and after tribocorrosion tests at open circuit potential in $0.6 \mathrm{M} \mathrm{NaCl}$. Inset shows data for A20 plotted on a smaller potential scale for better visualization. 
(a)

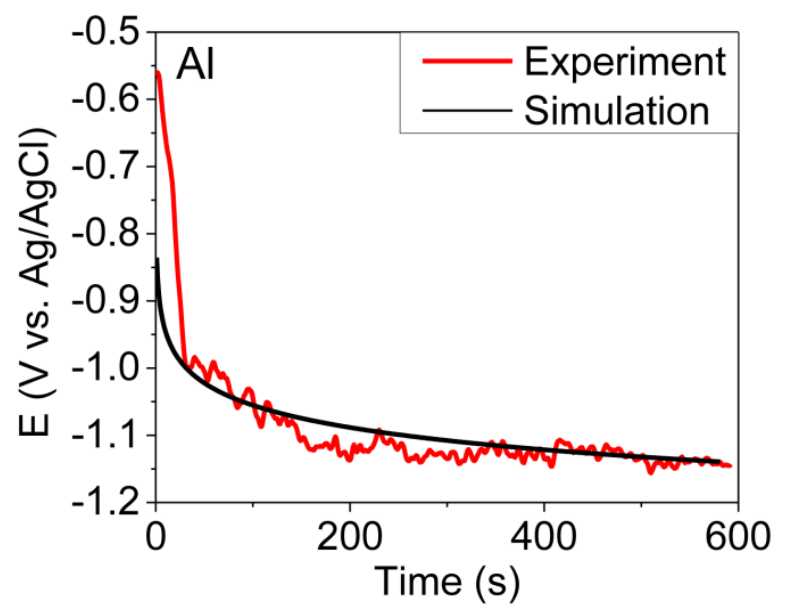

(b)

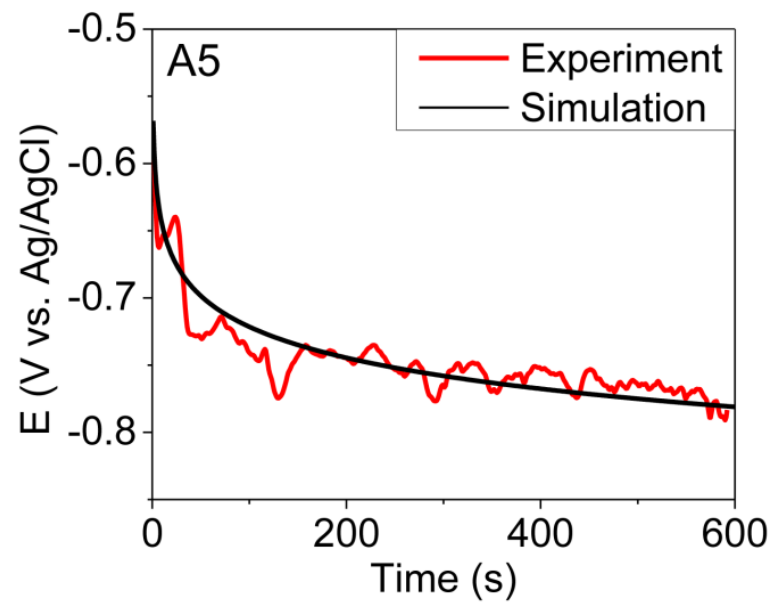

Figure 9. Experimental measurements (red curves) and model simulation (black curves) of potential evolution during tribocorrosion tests for (a) Al and (b) A5.

(a)

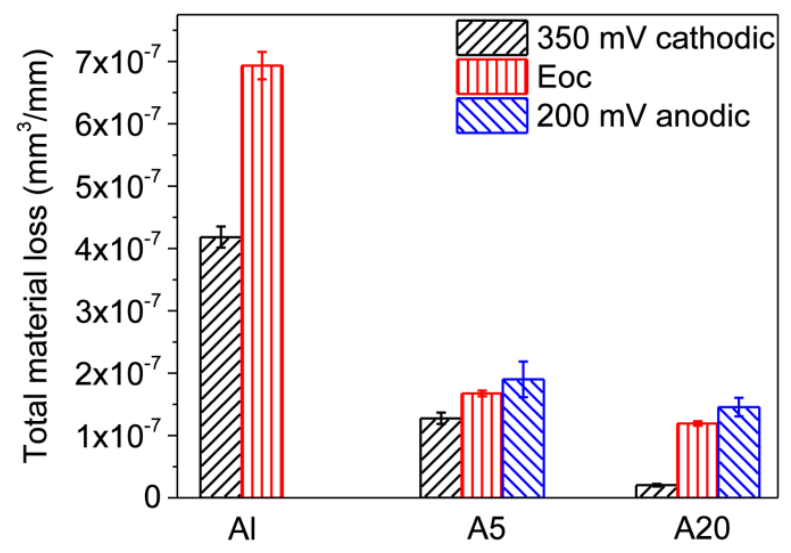

(b)

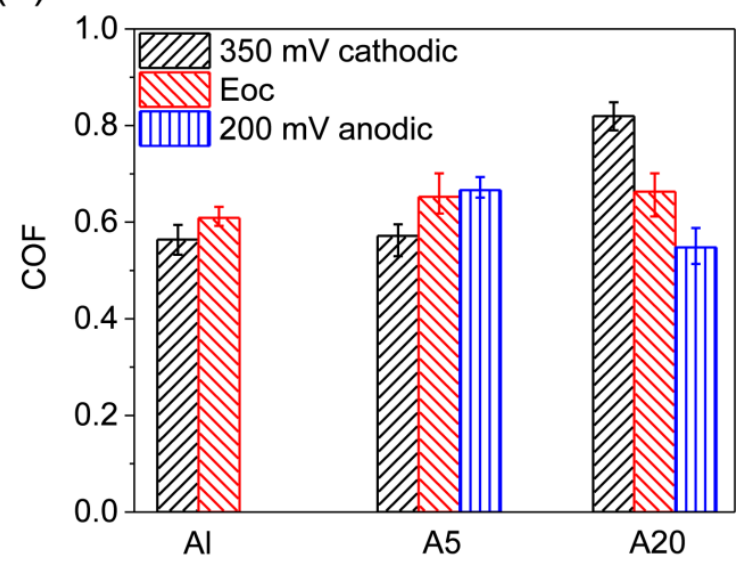

Figure 10. Summary of (a) the total material loss, and (b) COF of Al and Al-Mn alloys at various applied potentials. The average value of $\mathrm{E}_{\mathrm{OC}}$ is $-574.1,-442.8$, and $-459.2 \mathrm{mV}$ vs. $\mathrm{Ag} / \mathrm{AgCl}$ for $\mathrm{Al}$, $A 5$, and $A 20$, respectively. 


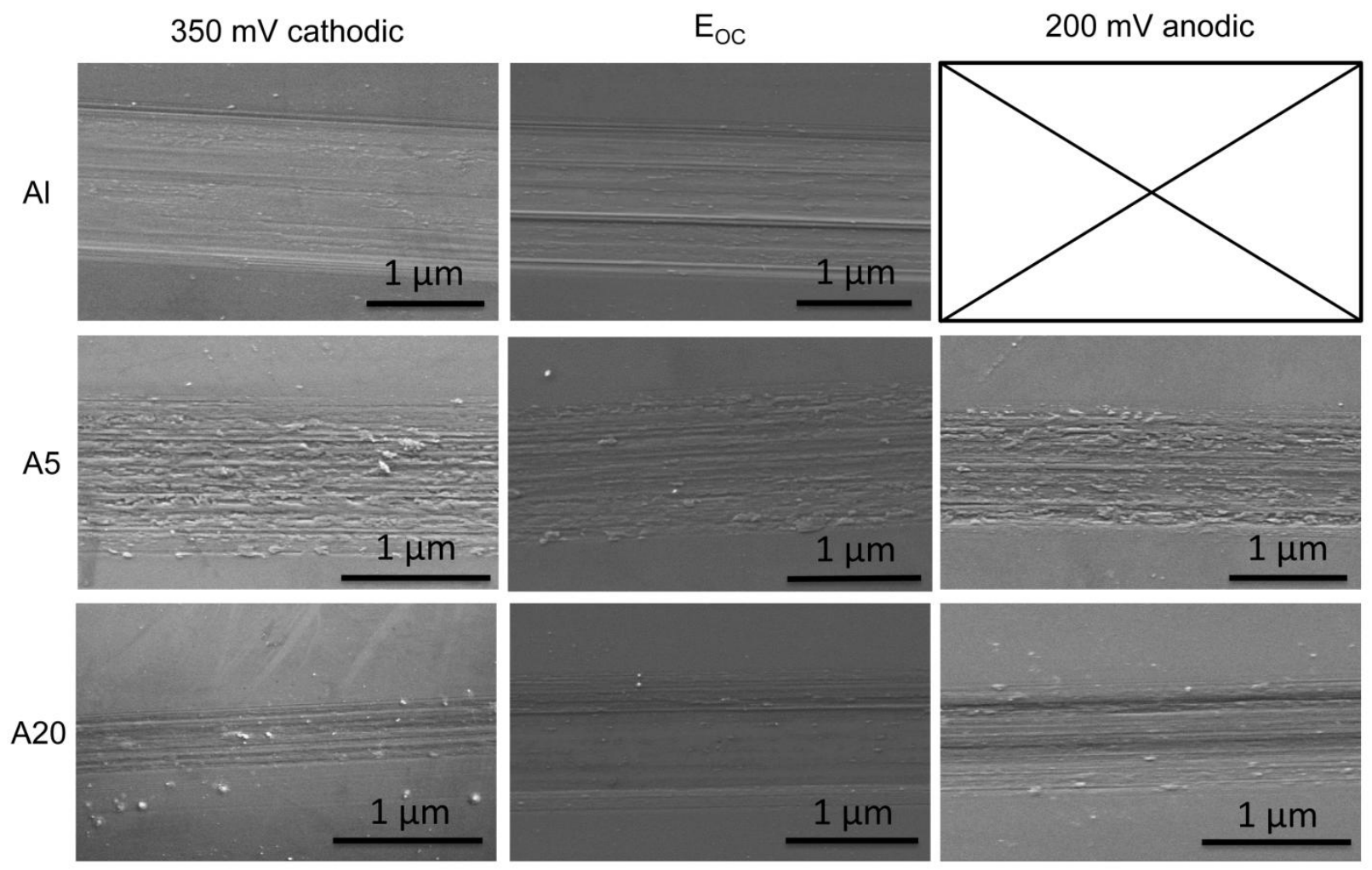

Figure 11. SEM images of the wear track formed on $\mathrm{Al}$ and $\mathrm{Al}-\mathrm{Mn}$ alloys in $0.6 \mathrm{M} \mathrm{NaCl}$ at different applied potentials. 
(a)

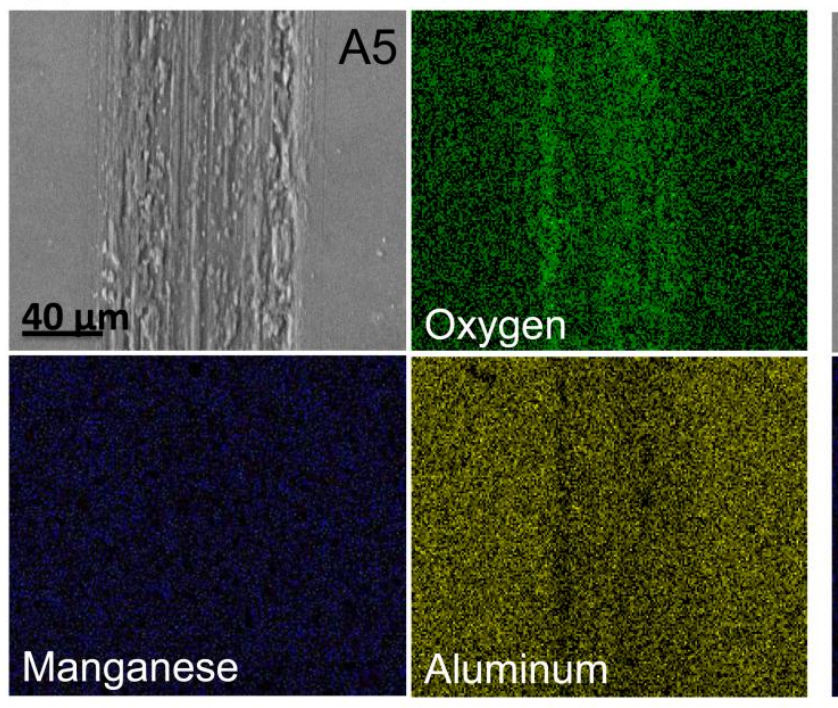

(b)

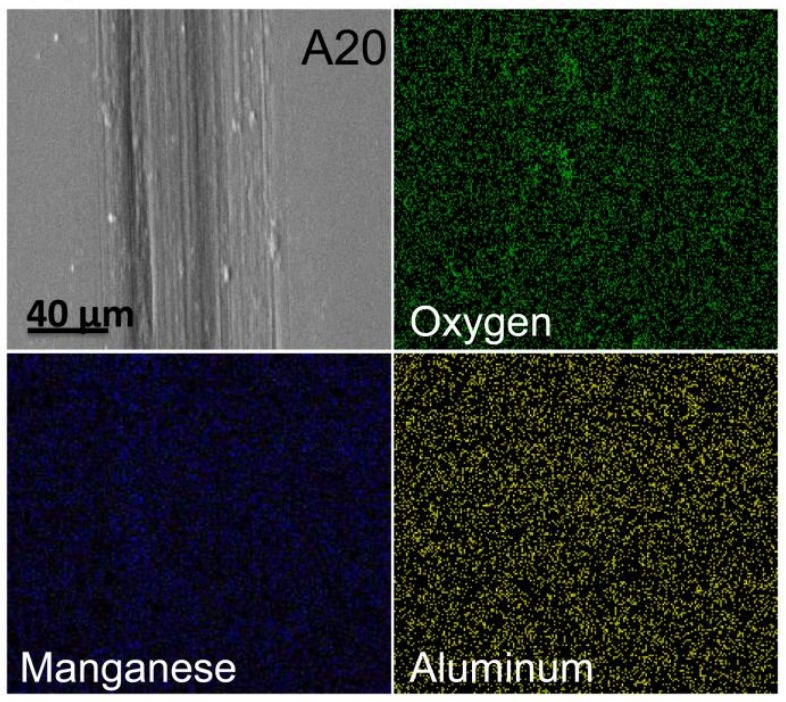

Figure 12. SEM image and the corresponding EDS element maps ( $\mathrm{O}, \mathrm{Mn}$ and $\mathrm{Al}$ ) of (a) A5 and (b) A20 after tribocorrosion at the anodic potential ( $200 \mathrm{mV}$ above their respective $\mathrm{E}_{o c}$ ). 


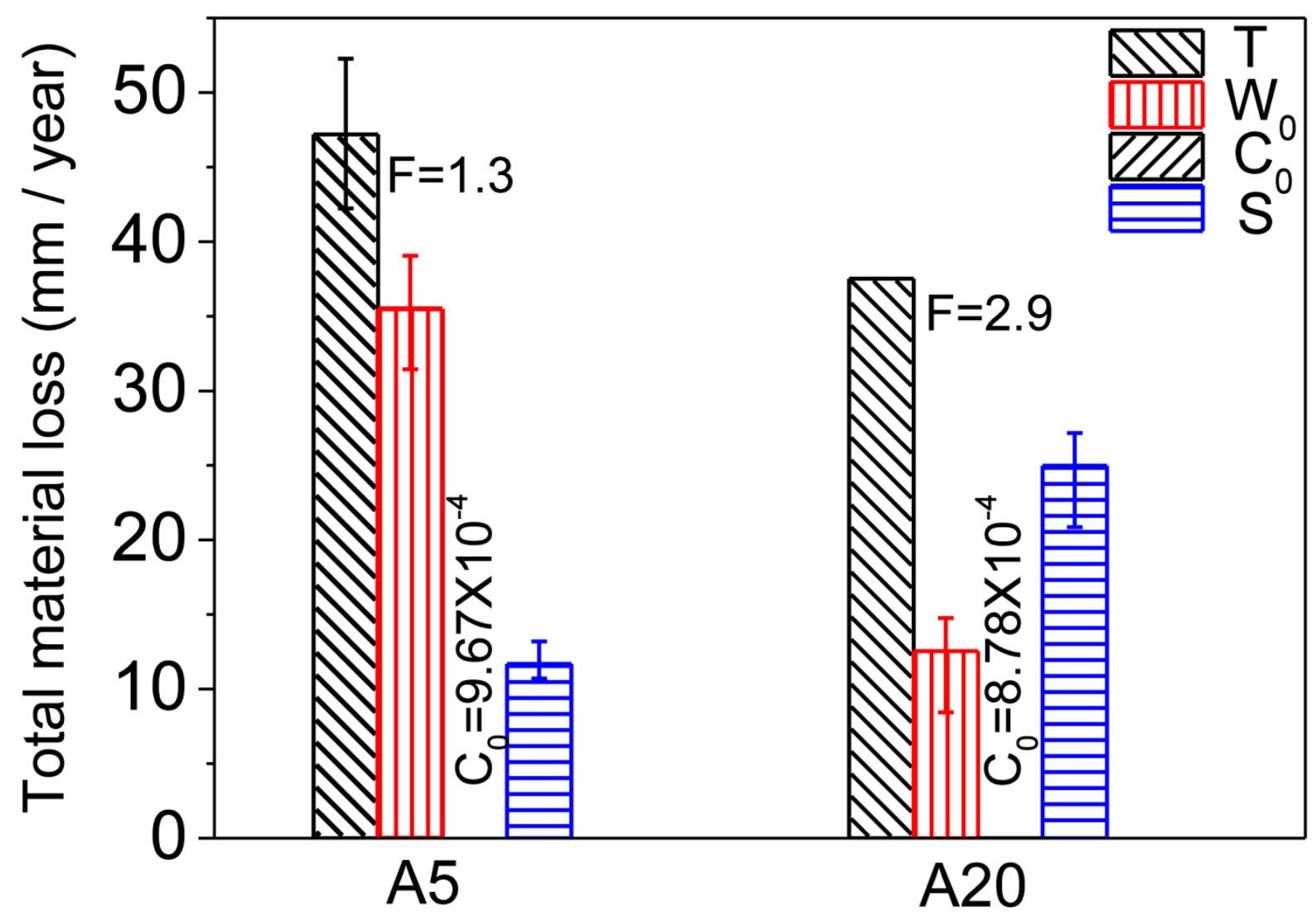

Figure 13. Synergetic contributions of the mechanical wear and corrosion of the amorphous and crystalline Al-Mn alloys in $0.6 \mathrm{M} \mathrm{NaCl}$. The total material loss $(\mathrm{T})$ was measured at the open circuit potential. 
(a)

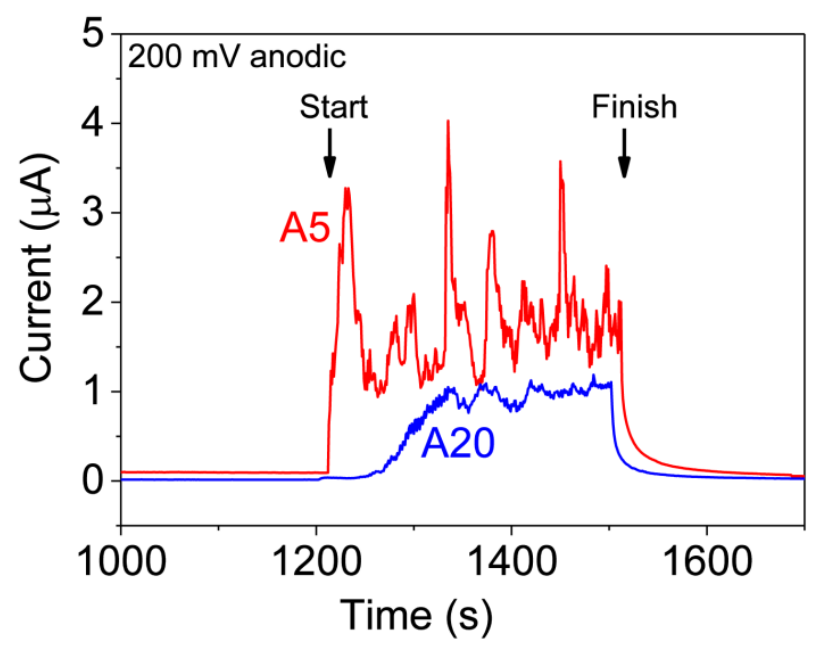

(b)
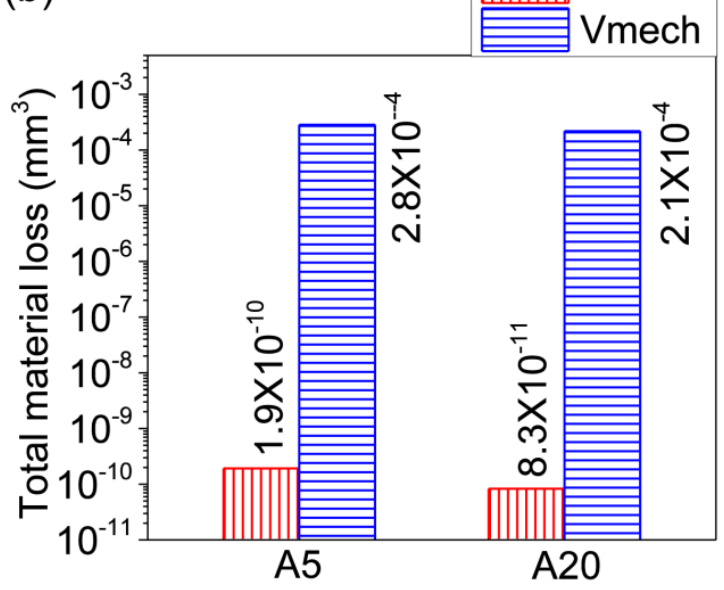

Figure 14. (a) Current evolution and (b) chemical and mechanical wear of A5 and A20 during tribocorrosion under anodic applied potential. 